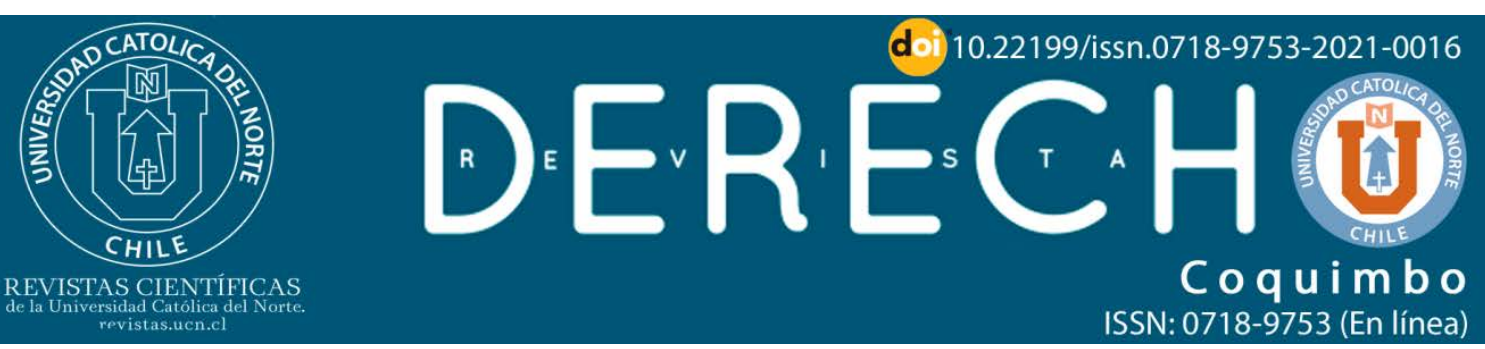

\title{
Bases normativas para un protocolo de atención a usuarios indígenas en los tribunales chilenos: especial referencia a los Juzgados de Policía Local.
}

\section{Normative basis for an attention protocol for indigenous users in}

Chilean tribunals: special reference to Local Police Judges.

\author{
Lavinia Francesconi' ${ }^{1}$ (D) https://orcid.org/0000-0003-1343-293X \\ Myrna Villegas Díaz² (D) https://orcid.org/0000-0001-9874-7396
}

'Estudiante de doctorado. Magister LL.M. Public International Law de la Facultad de Derecho de la Rijksuniversiteit Leiden. francesconi.lavinia@gmail.com

${ }^{2}$ Universidad de Chile, Santiago, Chile. Departamento de Ciencias Penales. Profesora Asociada e investigadora. Doctora en Derecho por la U. de Salamanca.@mvillegas@derecho.uchile.cl

\section{Resumen:}

Los sistemas normativos de Latinoamérica reconocen los derechos de los pueblos indígenas dando vida a un área específica de estudio del derecho. En algunos lugares donde estos derechos se encuentran mejor desarrollados se han diseñado modelos de atención indígena para los integrantes de las comunidades acorde a sus necesidades y características culturales. La comparación entre estos sistemas, junto con el análisis de la normativa internacional y nacional chilena, permiten perfilar las bases normativas que podrían sustentar la elaboración de un protocolo de atención específico para usuarios indígenas ante tribunales chilenos, que contribuya a minimizar la brecha de desigualdad existente.

Palabras Clave: Buenas prácticas; Acceso a la justicia; Derechos lingüísticos. (cc) BY 


\section{Introducción}

La relación del Estado de Chile con sus pueblos indígenas no ha estado exenta de dificultades, volviéndose particularmente compleja en los tribunales, tanto cuando los indígenas acuden a la justicia oficial buscando que se respeten sus derechos como cuando son requeridos en calidad de infractores. De ahí la necesidad de adoptar medidas con pertinencia cultural desde el primer contacto presencial de los/las usuarios/as indígenas con el tribunal, como un protocolo de atención que recopile buenas prácticas y proporcione algunos criterios a los actores del sistema de justicia, acorde con los estándares internacionales de derechos humanos sobre no discriminación e igualdad.

Para ello y en la búsqueda de los fundamentos normativos para un protocolo de atención para usuarios indígenas, se describe y examina el marco legal internacional, comparado y nacional que justifica y sugiere su adopción. Se identifican comunes denominadores y principios básicos en la normativa internacional tanto universal como regional que puedan servir como orientaciones a los actores del sistema de Justicia. Se revisa también la normativa interna de ocho países latinoamericanos: México, Guatemala, Colombia, Paraguay, Ecuador, Brasil, Perú y Bolivia, cuya elección obedece a la alta presencia de indígenas en sus territorios. Finalizaremos con el examen de la normativa nacional chilena, con especial atención en los Juzgados de Policía Local, para proponer las bases normativas mínimas de un protocolo de atención con pertinencia cultural indígena en aquellas instituciones. Se escogen estos tribunales por cuanto la investigación en cuyo marco se confeccionó este trabajo consideró la realidad de algunos municipios con Alcalde Mapuche en la Región de Araucanía, entre los años 2017-2019, dando origen al Protocolo de Atención con pertinencia cultural a usuarios y usuarias mapuche en los tribunales y juzgados de la Macro región Sur (Equipo FONDEF ID 16I10424, s. f.; Sobre el trabajo etnogáfico que lo sustenta, ampliamente Martínez Cañoles, 2019). En este trabajo se profundiza en los fundamentos normativos de dicho protocolo.

\section{Normativa internacional}

El derecho internacional de los derechos humanos reconoce los derechos de los pueblos indígenas como parte de un proceso mundial tendiente a resguardar la paz y la estabilidad (Anaya, 2009a, pp. 52-53), estableciendo como deber a los Estados su respeto y promoción. Para ello ha dictado algunos instrumentos internacionales específicos tales como el Convenio № 169 de la Organización Internacional del Trabajo sobre pueblos indígenas y tribales de 1991, la Declaración de Naciones Unidas sobre los Derechos de los Pueblos Indígenas de 2007, y la Declaración Americana sobre los Derechos de los Pueblos Indígenas de 2016. Sus ejes rectores son la igual- 
dad y no discriminación en cuanto fundamento del reconocimiento de la identidad, la autonomía y sus derechos territoriales. Igualdad y no discriminación se presentan en los tratados internacionales como las dos caras de la misma moneda, pues la igualdad en el trato o de oportunidades, supone a su vez la no discriminación en ellos (Declaración Universal de Derechos Humanos, 1948, art. 1 y 2; Declaración de Naciones Unidas sobre los Derechos de los Pueblos Indígenas, 2007, art. 2; Convención Interamericana contra el racismo, la discriminación racial y formas conexas de intolerancia, 2013, art. 1; Convención Interamericana para prevenir, sancionar y erradicar la violencia contra la mujer, 1994, art. 6)-, cobrando especial relevancia la igualdad ante la ley y la igualdad de género (Declaración de Naciones Unidas sobre los Derechos de los Pueblos Indígenas, 2007, arts. 22 y 44 y en el Pacto Internacional de Derechos Civiles y Políticos, 1976, art. 3).

La igualdad, en tanto principio derivado de la dignidad humana, conlleva la prohibición de tratar en forma diferente a un grupo por considerarlo superior o inferior a otro -Norín Catrimán y otros (dirigentes, miembros y activista del pueblo indígena mapuche) Vs. Chile (2014, párr. 197). Antes ya lo había afirmado en Atala Riffo y Niñas Vs. Chile. (2012, párr. 79) y en la Propuesta de modificación a la Constitución Política de Costa Rica relacionada con la naturalización (1984, párr. 53)-. La discriminación es toda distinción, exclusión, restricción o preferencia basada en ciertas categorías prohibidas (dentro de las cuales está el "origen étnico"), que tenga por objeto o resultado anular o menoscabar el reconocimiento, goce o ejercicio, en igualdad de condiciones, de los derechos humanos en cualquier esfera (política, económica, social, cultural, entre otras) (Norín Catrimán y otros (dirigentes, miembros y activista del pueblo indígena mapuche) Vs. Chile (2014, párrs., 198, 202 y 203).

Para garantizar la promoción y salvaguarda de los mismos, los Estados tienen el deber de adoptar medidas específicas y adecuadas (Declaración Universal de Derechos Humanos, 1948, art. 7; Pacto Internacional de Derechos Civiles y Políticos, 1976, art. 26; Convención Internacional sobre la Eliminación de todas las Formas de Discriminación Racial, 1969, art. 5; Convención sobre la eliminación de todas las formas de discriminación contra la mujer, 1981, art. 15; Convención Interamericana contra el racismo, la discriminación racial y formas conexas de intolerancia, 2013, art. 2; Convención Americana sobre Derechos Humanos, 1978, art. 24; Convención Interamericana para prevenir, sancionar y erradicar la violencia contra la mujer, 1994, art. 4 inc. f) con el fin de remediar "...la desigualdad resultante..." (Shelton, 2008, p. 26) de grupos discriminados, entre ellos, los indígenas. Ver Declaración de Naciones Unidas sobre los Derechos de los Pueblos Indígenas (2007, art. 21 y art. 13, no. 2); Pacto Internacional de Derechos Civiles y Políticos (1976, art. 2); Convención Internacional sobre la Eliminación de todas las Formas de Discriminación Racial (1969, art. 2); Convención Americana sobre Derechos Humanos (1978, art. 2); Convención sobre la eliminación de todas las formas de discriminación contra la mujer (1981, art. 2, e y f, arts. 3 y 24); Convenio No 169 (1991, art. 4); Convención Interamericana contra el racismo, la discriminación racial y formas 
conexas de intolerancia (2013, arts. 5, 6, 7 y 9); Convención Interamericana para prevenir, sancionar y erradicar la violencia contra la mujer (1994, arts. 7 y 8). Véliz Fanco y otros Vs. Guatemala (2014, párr. 206); Atala Riffo y Niñas Vs. Chile. (2012, párr. 80); Norín Catrimán y otros (dirigentes, miembros y activista del pueblo indígena mapuche) Vs. Chile, 2014, párr. 201).

En el ámbito judicial cobra relevancia el derecho de acceso a la justicia (Convenio No 169, 1991, arts. 8, 9 y 12; Convención Americana sobre Derechos Humanos ,1978, art. 8, no. 1 en relación con el art. 25, no. 1; Declaración de Naciones Unidas sobre los Derechos de los Pueblos Indígenas, 2007, arts. 13 y 40; Pacto Internacional de Derechos Civiles y Políticos, 1976, art. 14, no. 1; Convención Interamericana para prevenir, sancionar y erradicar la violencia contra la mujer, 1994, art. 7, g; Convención Interamericana contra el racismo, la discriminación racial y formas conexas de intolerancia, 2003, art. 10), pues permite la ejecución, protección y defensa de todos los otros derechos consagrados en instrumentos internacionales (Birgin y Kohen, 2006, p. 16). Por ejemplo, el respeto a garantías procesales mínimas (Convención Americana sobre Derechos Humanos, 1978, art. 8; Pacto Internacional de Derechos Civiles y Políticos, 1976, art. 14, no. 3; Declaración Universal de Derechos Humanos, 1948, art. 10 y 11), derecho a un juez imparcial, a ser juzgado sin dilaciones; derecho a defensa, a no ser obligado a declararse culpable; a ser informado sobre los cargos imputados en un idioma que la persona comprenda (Pacto Internacional de Derechos Civiles y Políticos, 1976, art. 14, no. 3, a; Declaración de Naciones Unidas sobre los Derechos de los Pueblos Indígenas, 2007, art. 13, no. 2).; a ser asistido por un intérprete (Convenio No 169, 1991, art. 12; Convención Americana sobre Derechos Humanos, 1978, art. 8; Declaración de Naciones Unidas sobre los Derechos de los Pueblos Indígenas, 2007, art. 13, no. 2); Pacto Internacional de Derechos Civiles y Políticos, 1976, art. 14, no. 3, a y f) cuando la persona no entienda el idioma, entre otros.

Pero también deben considerarse el derecho propio y costumbres de los pueblos indígenas, pues forman parte del corpus iuris internacional, desde que tanto el Convenio No 169 (1991, arts. 8 y 9); como la Declaración de Naciones Unidas sobre los Derechos de los Pueblos Indígenas (2007, art. 13, no. 2, art. 34 al 40); y el Pacto Internacional de Derechos Civiles y Políticos (1976, art. 27) hacen un reenvío explícito a ellos al ordenar a los Estados respetarlas en la medida que sean compatibles con los derechos humanos. De esta forma, la cosmovisión indígena debe ser considerada en los recintos judiciales, lo que implica que puedan ocupar sus vestimentas tradicionales en las dependencias judiciales incluso durante las audiencias; portar y eventualmente usar sus instrumentos ceremoniales; comunicarse en su propia lengua a través de la colaboración de intérpretes y traductores; ser asistidos lingüísticamente en juicio por miembros de su comunidad que ellos elijan; autorización para el ingreso de miembros de las comunidades en las audiencias públicas; desarrollar rituales antes de un juicio en el recinto donde serán juzgados, entre otros. 
Esto también es relevante tratándose de niños, niñas y adolescentes indígenas, dado que la cosmovisión indígena considera a los niños como partícipes activos de las comunidades desde muy corta edad. Es frecuente observar a niños acompañando a sus padres a tribunales (Martínez Cañoles, 2019, p. 74), incluso cuando asisten a audiencias; o a adolescentes solicitando información, o presentes en audiencias donde se juzga a algún miembro de su comunidad, o eventualmente como víctimas o infractores, dado que a temprana edad asumen responsabilidades al interior de la comunidad. Ninguno de ellos puede ser discriminado, por su edad y/o pertenencia a un pueblo indígena (Convención sobre los Derechos del Niño, 1990, art. 2, no. 1), reconociéndose el fuerte componente colectivo que tienen sus derechos (e.g. Convención sobre los Derechos del Niño, 1990, art. 30).

Por ello, el interés superior de niños, niñas y adolescentes indígenas (Convención sobre los Derechos del Niño, 1990, art. 3) debe apreciarse desde el enfoque cultural y entorno específicos donde se desenvuelve (Harris-Short, 2012, p. 270), y se "... concibe como un derecho colectivo y como un derecho individual..." (Observación General N ${ }^{\circ} 11,2009$, no. 30). Todo(a) niño, niña y adolescente indígena tiene derecho a ser escuchado y tenido en cuenta en todo procedimiento judicial (Convención sobre los Derechos del Niño, 1990, art. 12, no. 2); a ser satisfecho en sus necesidades lingüísticas mediante el acceso gratuito a un intérprete (Convención sobre los Derechos del Niño, 1990, art. 40 no. 2, vi); al contacto con sus familias y de acceso a asistencia judicial.

Debe tenerse presente también eventuales situaciones de discriminación múltiple, como el caso de los niños, niñas y adolescentes indígenas con discapacidad (Observación General N 9, 2007, párr. 80), así como el de las mujeres indígenas, por su especial grado de vulnerabilidad (Stavenhagen, 2007, J) producto de la triple opresión de que son objeto: mujer, indígena y pobre (ampliamente en Lagarde y de los Ríos (1988; y 1993).

El acceso a la justicia representa una de las principales problemáticas y fuente de vulneración de los derechos de los pueblos indígenas, mediante diversas formas de discriminación en la aplicación práctica y funcionamiento del sistema. Una de ellas tiene que ver con el componente lingüístico dado que "El idioma de las actuaciones judiciales suele ser un problema para la debida protección de los derechos de los indígenas" (Stavenhagen, 2004, párr. 37), de manera tal que en países en los que los idiomas indígenas no están reconocidos oficialmente y su uso no está normalizado en sus instituciones judiciales, hay de facto una discriminación. Ello no dice relación con que el indígena domine o no el idioma oficial, sino con la comprensión del significado de ciertas construcciones lingüísticas. Si para una persona no indígena es complejo entender el funcionamiento de un proceso judicial o de determinadas instituciones, imaginemos como lo será para un indígena cuyo idioma materno no es el castellano. 
Una de las formas de solución a este problema, tal como lo han recomendado los relatores de pueblos indígenas de Naciones Unidas, es contar con traductores bilingües y “...facilitadores o guías judiciales" (Stavenhagen, 2004, párr. 40), capacitados en los procesos en los que estén presente pueblos indígenas, independientemente del rol que tenga en dicho proceso.

Existen también algunas problemáticas sectoriales concretas puestas de relieve por los organismos de derechos humanos, que dificultan el acceso igualitario, eficaz y garantista a la justicia por parte del pueblo indígena mapuche, y que han generado en ellos una percepción de injusticia y de discriminación. Tales son por ejemplo la aplicación de la ley de conductas terroristas (Emmerson, 2014, párr. 43), la violencia policial sistemática contra las comunidades en el marco del conflicto territorial, y la estigmatización de sus miembros frente a las autoridades (Anaya, 2009b, párr. 58). El acceso a la justicia con pertinencia cultural, en estos casos, debe ir acompañado de una reducción de la violencia discriminatoria y del fomento de la confianza con los cuerpos de seguridad del Estado.

\section{Experiencias comparadas ${ }^{1}$}

A nivel regional, y en general, la realidad indígena goza de un alto reconocimiento a nivel legislativo, especialmente constitucional, así como respecto de la atención y el trato que los usuarios indígenas del sistema de justicia debiesen recibir.

\subsection{Experiencias comparadas a nivel constitucional y legal}

Todos los países analizados, con excepción de Honduras -cuya Constitución (1982) no reconoce de forma explícita a los pueblos indígenas, pero sí hace mención a la diversidad cultural del país (arts. 173 y 346) así como otras cuestiones relacionadas a la materia (Aguilar Cavallo, Lafosse, Rojas Corral y Steward 2010, p. 93). - reconocen constitucionalmente el carácter pluricultural o plurinacional de sus Estados, basados en la preexistencia de los pueblos indígenas en sus territorios, así como el derecho de los pueblos indígenas a su autonomía y libre determinación. Reconocen el carácter pluricultural del Estado las Constituciones Políticas de los Estados Unidos Mexicanos (1917, art. 2), Guatemala (1985, art. 58) -además reconoce que "...está formada por diversos grupos étnicos entre los que figuran los grupos indígenas de ascendencia maya. El Estado reconoce, respeta y promueve sus formas de vida, costumbres [...], idiomas y dialectos..." (Constitución Política de la República de Guatemala, 1985, art. 66), entre otros-, Colombia (1991, art. 7), Paraguay (1992, cap. V) y Perú (1993, art. 2, no. 19), Nicaragua (2014), que indica:

\footnotetext{
${ }^{1}$ Se deja fuera a Brasil, que pese a reconocer constitucionalmente a sus pueblos indígenas y tener legislación variada relativa a la especificación y ejercicio de sus derechos, entre ellos, el reconocimiento a la justicia comunitaria a través del "Estatuto del Indio", no cuenta con protocolo específico de atención para el sistema de justicia.
} 
El Estado reconoce la existencia de los pueblos originarios y afrodescendientes, que gozan de los derechos, deberes y garantías consignados en la Constitución y en especial, los de mantener y desarrollar su identidad y cultura, tener sus propias formas de organización social y administrar sus asuntos locales;así como mantener las formas comunales de propiedad de sus tierras y el goce, uso y disfrute, todo de conformidad con la Ley. Para las comunidades de la Costa Caribe se establece el régimen de autonomía en la presente Constitución (art. 5, inc. 6).

A su vez, reconocen el carácter plurinacional del Estado, las Constituciones Políticas de Ecuador (2008, art. 1) y Bolivia (2009, art. 1).

De la mano con este reconocimiento está la afirmación también constitucional del principio de igualdad y la no discriminación de los pueblos indígenas, que en algunos países tiene una especial significación. Así por ejemplo, en la Constitución colombiana (1991) la igualdad se concibe en tres sentidos: como no discriminación, como promoción de medidas positivas para la mejora de la situación vulnerable de los indígenas, y como "derecho a la diferencia", esto es, medidas enfocadas al "respeto y reconocimiento de la diferencia cultural" (Botero Marino, 2008, p. 157). A su vez, la Constitución ecuatoriana (2008) junto con garantizar la igualdad en el ejercicio y goce de los derechos (art. 11, no. 2) y la prohibición de toda forma de discriminación para todas las personas (art. 66, no. 4), reconoce como derecho colectivo de los pueblos indígenas el "No ser objeto de racismo ni de ninguna forma de discriminación..." (Constitución de la República del Ecuador, 2008, art. 57 no. 2). También la Constitución de Paraguay (1992) consagra la prohibición de toda forma de discriminación, señalando que "El Estado removerá los obstáculos e impedirá los factores que las mantengan o las propicien" (art. 46). La Constitución de los Estados Unidos Mexicanos (1917) prohíbe expresamente “...toda discriminación motivada por origen étnico o nacional..." (art. 1 inc. 5) y la Constitución de Bolivia (2009), también contempla la prohibición de "...toda forma de discriminación..." (art. 14, II), concretándose el mandato constitucional en la Ley contra el racismo y toda forma de discriminación que, como política preventiva de la discriminación, en el ámbito de la administración pública, señala entre otras, la "Adopción de procedimientos o protocolos para la atención de poblaciones específicas" (Ley Nº45, 2010, art. 6, II, d).

Como consecuencia se reconoce también constitucionalmente en varios de ellos la autonomía y la libre determinación, pero de manera restringida en aquellos Estados pluriculturales. Así por ejemplo en México se señala expresamente que esta autonomía debe ejercerse asegurando la unidad nacional, y que cada Estado federado recogerá constitucionalmente este régimen de autonomía (Constitución Política de los Estados Unidos Mexicanos, 1917, art. 2); en Nicaragua el régimen de autonomía, establece la Carta Magna (2014), debe ser regulado por ley estableciendo las atribuciones de los órganos de gobierno indígenas y su relación con el Poder Ejecutivo y Legislativo y con los municipios (art. 181). 


\subsubsection{El derecho de acceso a la justicia y su concreción legal}

Otra característica común en las legislaciones examinadas, que deriva del derecho de acceso a la justicia reconocido a los pueblos indígenas, es la afirmación constitucional del derecho a aplicar sus propios sistemas normativos en la regulación y solución de sus conflictos internos dentro de sus territorios. Así las Constituciones Políticas de los Estados Unidos Mexicanos (2017, art. 2); Colombia (1991, art. 246); Ecuador (2008, arts. 57, no. $10 ; 171$; y 17, no. 7, i), Paraguay (1992, art. 63), Perú (1993, art. 149) y Bolivia (2009, art. 30, II, no. 14, y arts. 190 y 191). En Perú, el derecho de las autoridades de comunidades campesinas y nativas a ejercer funciones jurisdiccionales se hace con el apoyo de las Rondas Campesinas (Ley N² 27.908, 2003; reglamentada en, Decreto Supremo $N^{\circ}$ 025, 2003). Y los jueces de paz están facultados para solicitar el apoyo de las rondas campesinas para la ejecución de sus decisiones (Ley $\mathrm{N}^{\circ} 29.824$, art. 6, no. 8). De manera similar, la Constitución boliviana reconoce a las instituciones indígenas (2009, art. 2), y el derecho a ejercer sus propios sistemas jurídicos (ampliamente, en Molina Rivero, 2008, p. 102), acorde a su cosmovisión. La jurisdicción indígena originaria se ejerce por sus propias autoridades y goza de igual jerarquía que la justicia ordinaria (Constitución Política del Estado plurinacional de Bolivia 2009, art. 179, II; Ley $\mathrm{N}^{\circ}$ 025, 2010, art. 4; Ley $\mathrm{N}^{\circ}$ 073, 2010, art. 3), debiendo el Estado promoverla y fortalecerla (Constitución Política del Estado plurinacional de Bolivia, 2009, art. 192. III). La Ley de Deslinde Jurisdiccional (Ley $N^{\circ} 073,2010$ ) regula los ámbitos de vigencia entre la jurisdicción indígena y las otras jurisdicciones y la que determina los mecanismos de coordinación y cooperación entre ellas.

El sometimiento a la jurisdicción indígena es facultativo o voluntario para el sujeto, y así se expresa en las Constituciones de Perú, Bolivia, Colombia, Ecuador (del Castillo Pinto, 2008, pp. 253-255) y Paraguay. El derecho de acceso a la jurisdicción indígena y su carácter facultativo en la Constitución paraguaya (1992) son reiterados en el Estatuto de las Comunidades Indígenas (Ley N 904, 1981, arts. 5 y 6). Los llamados para decidir si se extingue la acción penal en el caso de conflictos resueltos por comunidades indígenas son los jueces de paz (Ley $N^{\circ} 1.286,1998$, art. 44). Este último cuerpo legal contempla, además, un procedimiento especial para los hechos punibles relacionados con pueblos indígenas (Ley N 1.286, 1998, titulo VI).

En relación a la jurisdicción ordinaria, en general, las legislaciones examinadas aseguran el pleno acceso de los pueblos indígenas a ella, señalando expresamente que para garantizar este derecho se deben tener en consideración sus costumbres y especificidades culturales. Así ocurre por ejemplo en México -deber reforzado en el Código Federal de Procedimientos Civiles (1943, art. 222 bis), en el Código Nacional de Procedimientos Penales (2014, art. 410, inc. 7) y en el Código Penal Federal (1931, arts. 51 y 52)- y en Ecuador, cuyo Código Orgánico de la Función Judicial (2009) dispone una serie de principios de la justicia intercultural, tales como la diversidad, igualdad, ne bis in ídem, pro jurisdicción indígena e interpretación intercultural (Códi- 
go Orgánico de la Función Judicial, 2009, art. 344) (Trujillo Vásquez, 2012, p. 313). Incluso más, señala este cuerpo legal que se debe capacitar a las y los servidoras/es de la Función Judicial que actúen en zonas con predominio de pueblos indígenas, a fin “...de que conozcan la cultura, el idioma y las costumbres, prácticas ancestrales, normas y procedimientos del derecho propio y consuetudinario de los pueblos indígenas" (Código Orgánico de la Función Judicial, 2009, art. 346).

Establece también algunas directrices de interés al referirse a la jurisdicción ordinaria, señalando como principios orientadores el de responsabilidad, el de servicio a la comunidad, el de acceso a la justicia y el de interculturalidad. Según el principio de acceso a la justicia, los operadores de justicia son los responsables de cumplir con la obligación estatal de garantizar su acceso, derribando todas las barreras estructurales, culturales y de género, que sean discriminatorias e impidan la igualdad de acceso y de oportunidades (Código Orgánico de la Función Judicial, 2009, art. 22). Por otra parte, el principio de interculturalidad supone que "...las y los servidores de justicia deberán considerar elementos de la diversidad cultural relacionados con las costumbres, prácticas, normas y procedimientos de las personas, grupos o colectividades que estén bajo su conocimiento" (Código Orgánico de la Función Judicial, 2009, art. 24).

\subsubsection{Los derechos lingüísticos}

Sin duda, uno de los aspectos más desarrollados en estas legislaciones se refiere a los derechos lingüísticos de los pueblos indígenas. En no pocas legislaciones se reconocen, a la par que el idioma castellano como oficial, los idiomas de los pueblos indígenas, ya sea en todo el territorio nacional (ej. Paraguay, Ecuador) o en los lugares específicos donde habitan (ej. Colombia). Lo que acarrea la necesidad de dotar a los órganos jurisdiccionales oficiales de intérpretes y/o traductores para que estas personas puedan comunicarse en su propia lengua. Incluso en algunos países como Perú y Bolivia, se establece como requisito para ser juez en lugares con alta densidad poblacional indígena, que domine la lengua nativa.

En la Constitución Política de los Estados Unidos Mexicanos (1917) se reconoce a "Los indígenas [...] el derecho a ser asistidos por intérpretes y defensores que tengan conocimiento de su lengua y cultura" (art. 2, VIII), garantías también contempladas en el Código Federal de Procedimientos Civiles (1943, arts. 180. inc. 2 y 271), en el Código Nacional de Procedimientos Penales (2014, arts. 45, 109, 110 inc. 2 y 113), en la Ley Agraria (1992, art. 164, IV) y en la Ley General de Derechos Lingüísticos de los Pueblos Indígenas (2003, art. 10). Esta última sitúa en un plano de igualdad el idioma castellano con las lenguas indígenas (Ley General de Derechos Lingüísticos de los Pueblos Indígenas, 2003, art. 4), pudiendo éstas ser utilizadas en "...cualquier asunto o trámite de carácter público..." (Ley General de Derechos Lingüísticos de los Pueblos Indígenas, 2003, art. 7), para lo cual el Estado, debe "Garantizar que las insti- 
tuciones, dependencias y oficinas públicas cuenten con personal que tenga conocimientos de las lenguas indígenas nacionales requeridas en sus respectivos territorios" (Ley General de Derechos Lingüísticos de los Pueblos Indígenas, 2003, art. 13, XII).

Tanta importancia tienen estos derechos que la Ley Federal para Prevenir y Eliminar la Discriminación de 2003, reconoce como formas de discriminación el impedir el ejercicio del derecho a ser asistido por "...intérpretes o traductores en los procedimientos [...] judiciales..." (Ley Federal para Prevenir y Eliminar la Discriminación, 2003, art. 9, XII) y así también, el "Restringir o limitar el uso de su lengua, usos, costumbres y cultura en actividades públicas o privadas... (Ley Federal para Prevenir y Eliminar la Discriminación, 2003, art. 9, XXV). Por ello, el Estado debe implementar “...medidas de nivelación [...], inclusión y las acciones afirmativas necesarias para garantizar [...] el derecho a la no discriminación" (Ley Federal para Prevenir y Eliminar la Discriminación, 2003, art. 15 Bis), señalando como ejemplo de las primeras, el "Uso de intérpretes y traductores de lenguas indígenas" (Ley Federal para Prevenir y Eliminar la Discriminación, 2003, art. 15 Quáter, V) y de las segundas, "Las acciones de sensibilización y capacitación dirigidas a integrantes del servicio público con el objetivo de combatir actitudes discriminatorias" (Ley Federal para Prevenir y Eliminar la Discriminación, 2003, art. 15 Sextus, IV). Por último, la Ley para el Tratamiento de Menores Infractores, para el Distrito Federal en Materia Común y para toda la República en Materia Federal $(1991)^{2}$ prevé normas especiales para menores indígenas, en cuya virtud éstos tienen "...derecho a ser asistidos por intérpretes y defensores que tengan conocimiento de su lengua y cultura. (arts. 3), Villegas Díaz (2012), se refeire ampliamente a este tema.

En Guatemala tanto el Código Procesal Civil y Mercantil (Decreto Ley № 107, 1963, art. 163) como el Código Procesal Penal (Decreto N 51-92, 1992, art. 90) reconocen el derecho de los indígenas de ser asistidos por un intérprete. En el ámbito civil y mercantil es designado por el juez, mientras que en el ámbito penal el imputado puede elegir a alguien de su confianza (Decreto Ley $N^{\circ} 107,1963$, art. 163). En este último cuerpo normativo, se destaca el mandato de que "...los actos procesales deberán realizarse también en idioma indígena y traducidos al español simultáneamente [...] las resoluciones como las actas se redactarán en ambos idiomas" (Decreto $\mathrm{N}^{\circ} 51,1992$, art. 142).

Este deber se contempla también en la Ley de Idiomas Nacionales (Decreto $\mathrm{N}^{\circ}$ 19, 2003, art. 9), la cual establece además, que se tiene que facilitar el acceso a los servicios como el de justicia, para los cuales los integrantes de pueblos indígenas deben ser informados y atendidos en el idioma propio (Decreto $\mathrm{N}^{\circ} 19,2003$, art. 15). Por esta razón, los postulantes a puestos públicos deberán, además del castellano, “...hablar, leer y escribir el idioma de la comunidad lingüística respectiva donde

\footnotetext{
${ }^{2}$ Ley abrogada en el Diario Oficial Federal el 16 de junio de 2016.
} 
realicen sus funciones..." (Decreto $N^{\circ} 19,2003$, art. 16), mientras que los servidores públicos en ejercicio, deben ser capacitados para que, como indica el texto legal, la prestación del servicio se tenga "...pertinencia cultural y lingüística..." (Decreto N ${ }^{\circ}$ 19, 2003, art. 16). Cabe recordar que en este país, el reconocimiento de los derechos de los pueblos indígenas fue una conquista política, mediante los Acuerdos de Paz según la Ley Marco de los Acuerdos de Paz, éstos son compromisos del Estado (Decreto $N^{\circ}$ 52, 2005, art. 3)- celebrados entre el Gobierno Guatemalteco y la Unidad Revolucionaria Nacional Guatemalteca, los que incluyeron los derechos indígenas e identidad cultural (ampliamente en Roht-Arriaza, 2017, p. 446).

En Nicaragua, el texto constitucional consagra el derecho a la educación intercultural en su lengua materna para los pueblos indígenas y las comunidades étnicas de la Costa Atlántica (2014, art. 121). Y la Ley de Trato Digno y Equitativo a Pueblos Indígenas y Afro Descendientes (Ley $N^{\circ} 757,2011$ ), al garantizar iguales oportunidades en el acceso al trabajo (art. 1), y la protección contra todo tipo de discriminación (art. 7); establece expresamente la prestación de servicios en las lenguas oficiales de las respectivas comunas por parte de las diversas instituciones (art. 6).

La Constitución Política de la República de Colombia (1991) reconoce a las lenguas y dialectos indígenas como lenguas oficiales en sus territorios (art. 10). La Ley de Lenguas Nativas (Ley $N^{\circ} 1.381,2010$ ) señala que tendrán derecho a actuar en su propia lengua cuando comparezcan ante órganos del poder judicial, garantizándose que sean asistidos gratuitamente por intérpretes y defensores "...con conocimiento de su lengua y cultura" (art. 7), derecho que está reconocido también en el Código de Procedimiento Penal (Ley N ${ }^{\circ}$ 906, 2004, arts. 8, 11 y 144) y en el Código de Procedimiento Civil (Decretos No 1.400 y 2.019, 1970, art. 192) ${ }^{3}$.

En la Constitución de la República del Ecuador (2008) se reconocen como idiomas oficiales el castellano, el kichwa y el shuar. Los demás idiomas ancestrales son de uso oficial para los pueblos indígenas en las zonas donde habitan (art. 2). Es también un derecho constitucional el "Ser asistido gratuitamente por una traductora o traductor o intérprete..." (Constitución de la República del Ecuador, 2008, art. 76, no. 7, f). Esta garantía es reafirmada en el Código de Procedimiento Penal (2000, art. 13) y el Código de Procedimiento Civil ${ }^{4}$ (2005, art. 264). La Constitución de la República del Paraguay (1992), reconocen como idiomas oficiales el castellano y el guaraní (art. 140), y el derecho a ser asistido por intérprete (Código Procesal Penal, 1998, arts. 7 y 119; y Código Procesal Civil, 1988, arts. 105 y 299).

La Constitución Política de Perú (1992) reconoce como “...idiomas oficiales el castellano, y en las zonas donde predominen, [...] el quechua, el aimara y las demás lenguas aborígenes..." (art. 48). La Ley № 29.735 regula los derechos lingüísticos

\footnotetext{
${ }^{3}$ Derogado por la Ley No 1.564 de 2012.

${ }^{4}$ Derogado por Código Orgánico General de Procesos de 2016.
} 
consagrando el derecho de las personas a ser atendidas "...en su lengua materna en los organismos e instancias estatales" (Ley $N^{\circ} 29.735,2011$, art. 4.1, f), así como de "...disponer de los medios de traducción directa o inversa que garanticen el ejercicio de sus derechos en todo ámbito" (Ley N²9.735, 2011, art. 4.1, g), entre otros. Para estos efectos, las entidades que prestan servicios públicos deben implementar políticas y programas de capacitación para que "...sus funcionarios y servidores públicos, así como los integrantes de las Fuerzas Armadas y de la Policía Nacional del Perú se pueden comunicar [...] en esa lengua" (Ley $N^{\circ} 29.735,2011$, art. 15.2). En el ámbito de la jurisdicción penal ordinaria, también se establece el derecho a ser asistido por traductor o intérprete (Decreto Legislativo $N^{\circ} 957,2006$, arts. 114 y 115) y se tipifica como delito, la discriminación por razones étnicas y culturales (entre otras), con penas más graves si el agente es funcionario o servidor público (Decreto Legislativo $\mathrm{N}^{\circ}$ 635,1991 , art. 323).

Un instrumento muy relevante en esta materia es la Hoja de Ruta de la Justicia Intercultural (2012), aprobada por la Corte Suprema, que crea la Dirección Nacional de Justicia Intercultural, cuyo objetivo "...es contribuir al reconocimiento e interacción de los sistemas de justicia que operan en el país" (Perú) (Hoja de Ruta de la Justicia Intercultural, 2012, no. 3). Para ello debe, entre otras cosas: "Promover programas de formación sobre justicia intercultural para los operadores del Poder Judicial..." (Hoja de Ruta de la Justicia Intercultural, 2012, no. 3, h); "Propiciar espacios de información, formación e investigación sobre la justicia intercultural, a través de módulos de capacitación especializada en la Academia de la Magistratura..." (Hoja de Ruta de la Justicia Intercultural, 2012, no. 4) así como de la consideración de “...aspectos relativos al desarrollo de la justicia intercultural..." (Hoja de Ruta de la Justicia Intercultural, 2012, no. 5) en la planificación de actividades administrativas. Para ser Juez de Paz, es requisito "Conocer además del castellano, el idioma quechua o aymara o cualquier otro dialecto, si en el lugar donde va a actuar, predomina uno de ellos" (Decreto Supremo № 017, 1993, art. 183, no. 5).

Finalmente, la Constitución Boliviana (2009) reconoce como "... idiomas oficiales del Estado el castellano y todos los idiomas de las naciones y pueblos indígena originario campesinos..." (art. 5, I). Esto implica que para poder acceder a desempeñar funciones públicas se requiere "Hablar al menos dos idiomas oficiales del país" (Constitución Política del Estado plurinacional de Bolivia, 2009, art. 234, no. 7), requisito que se reitera en la Ley del Órgano Judicial respecto a los funcionarios de los mismos (Ley $N^{\circ} 025,2010$, arts. 18, 47, 61, 91, 99 y 103) y en la Ley del Tribunal Constitucional Plurinacional, respecto a los magistrados y magistradas de dicha entidad (Ley $N^{\circ} 027$. 2010, art. 17). En ambos casos, para la calificación de méritos se tomará en cuenta el haber ejercido la calidad de autoridad originaria bajo su sistema de justicia. Asimismo, el texto constitucional garantiza a "Toda persona sometida a proceso debe ser juzgada en su idioma; excepcionalmente, de manera obligatoria, deberá ser asistida 
por traductora, traductor o intérprete" (Constitución Política del Estado plurinacional de Bolivia, 2009, art. 120, II).

\subsection{Experiencia comparada en materia de Protocolos de Atención a Usua- rios}

Para concretar lo declarado en sus respectivas constituciones y leyes, cada uno de los países analizados cuenta con protocolos de actuación específicos sobre atención a pueblos indígenas en el sistema de justicia.

En México existen varios instrumentos algunos federales y otros propios de algunos Estados, entre los cuales destacan, a nivel Federal: la aprobación del Protocolo Iberoamericano: de actuación judicial para mejorar el acceso a la justicia de personas con discapacidad, migrantes, niñas, niños, adolescentes, comunidades y pueblos indígenas (Suprema Corte de Justicia de la Nación, 2014); Protocolo de actuación: para quienes imparten justicia: en casos que involucren derechos de personas, comunidades y pueblos indígenas (Suprema Corte de Justicia de la Nación, 2013) ${ }^{6}$. A nivel de Estados federados: el Protocolo del Poder Judicial del Estado de Tabasco: para quienes imparten justicia en casos de personas, comunidades y pueblos indígenas (Poder Judicial del Estado de Tabasco, 2014) ${ }^{7}$, el Protocolo de actuación de justicia intercultural: Chiapas, México (Instituto Interamericano de Derechos Humanos, 2014a) ${ }^{8}$ y el Protocolo de actuación de justicia intercultural: Oaxaca, México (Instituto Interamericano de Derechos Humanos, 2014b) ${ }^{9}$.

En Guatemala encontramos el Protocolo de acceso a la justicia penal intercultural y coordinación interinstitucional, Guatemala (Instituto Interamericano de Derechos Humanos, 2015) ${ }^{10}$, y el "Manual de atención jurídica: área de atención integral de casos" (Presidencia de la República y Defensoría para la Mujer Indígena, s.f.) ${ }^{11}$. En Honduras destaca el "Protocolo Bio-cultural del Pueblo Indígena Miskitu: el derecho al consentimiento libre, previo e informado en nuestro territorio de La Muskitia Hondureña." (Mos-

\footnotetext{
${ }^{5}$ Dirigido al poder judicial en general, en especial al Presidente de la Corte Suprema y Tribunales Supremos de Justicia y a los máximos responsables de los Consejos de la Judicatura.

${ }^{6}$ Dirigido a funcionarios(as) del Poder Judicial de la Federación, es importante destacar el derecho que los indígenas tienen de acceder plenamente a la justicia que imparte el Estado.

${ }^{7}$ Destinado a Miembros del poder judicial, funcionarios y policías.

${ }^{8}$ Dirigido a Policía, Defensa Pública, Procuraduría, Poder Judicial o instituciones públicas con competencia complementaria de apoyo a la justicia.

${ }^{9}$ Destinado a Policía, Poder Judicial, Abogados, Instituciones Públicas que se relacionan con el pueblo Oaxaca.

${ }^{10}$ Fomenta una interpretación con perspectiva intercultural de Garantías y Derechos consagrados en la Constitución y la ley. Está dirigido a funcionarios(as) del sistema de justicia que laboran en el Organismo Judicial, Instituto de la Defensa Pública Penal, Ministerio Público y la Policía Nacional Civil, y que brindan atención y orientación a las personas y comunidades indígenas.

${ }^{11}$ Dirigido a personal profesional y técnico de la Unidad Jurídica de la defensoría de Mujeres Indígenas de Guatemala.
} 
quitia Asla Takanka, 2012) ${ }^{12}$. En Nicaragua existe el Protocolo de atención: Afrodescendientes (Procuraduría para la Defensa de los Derechos Humanos, 2012) ${ }^{13}$.

En Colombia destaca el Protocolo de orientación y asesoría: para las víctimas de violaciones de los derechos humanos y del derecho internacional humanitario pertenecientes a pueblos indígenas (Defensoría del Pueblo, 2011) ${ }^{14}$. Mientras que en Ecuador existe una Guía para la transversalización del principio de interculturalidad en la justicia ordinaria (Espinel Gaona, 2016) ${ }^{15}$. En Paraguay existe el Protocolo de actuación para una Justicia Intercultural: los pueblos indígenas (Prieto Giménez, 2017) ${ }^{16}$, y en Perú, el Protocolo de atención y orientación legal con enfoque intercultural: dirigido a funcionarios del sistema estatal de justicia (Consejo Ejecutivo del Poder Judicial, 2015) ${ }^{17}$, el Protocolo de atención y orientación legal con enfoque intercultural: dirigido a funcionarios de Ucayali y Loreto (Oficina Nacional de Justicia de Paz y Justicia Indígena del Poder Judicial, 2014) ${ }^{18}$, y los Protocolos de coordinación para una justicia intercultural. Protocolo de coordinación entre sistemas de justicia. Protocolo de actuación en procesos judiciales que involucren a comuneros y ronderos (Oficina Nacional de Justicia de Paz y Justicia Indígena del Poder Judicial, 2015) ${ }^{19}$.

\footnotetext{
${ }^{12}$ Para la atención del pueblo Miskitu, y obligatorio de aplicar por todos los agentes del Estado.

${ }^{13}$ Dirigido a funcionarios públicos para combatir el racismo, la discriminación, la exclusión y xenofobia hacia los afrodescendientes. Establece pautas de intervención para los(as) funcionarias en el abordaje de un caso de discriminación racial.

${ }^{14}$ Ofrece líneas de trabajo especialmente a los equipos "psicojurídicos" de la Unidad de Atención Integral a Víctimas, pero también a funcionarios de otras dependencias de la Defensoría concernidos en la exigibilidad de derechos de las personas y pueblos indígenas. Es un protocolo peculiar, pues entrega herramientas para atender a las necesidades de indígenas víctimas del conflicto armado interno.

${ }^{15}$ Editado bajo el Consejo de la Judicatura de Ecuador, es un documento que tiene como fin el de otorgar orientaciones para que la justicia ordinaria, en general, sea más inclusiva.

${ }^{16}$ Editado por la Corte Suprema de Justicia de Paraguay, contiene orientaciones y directrices para la actuación de los juzgados en los procesos judiciales concernientes a personas y comunidades indígenas, siendo una herramienta jurídica de acceso a la justicia con un enfoque de derecho y diversidad cultural relativa a los pueblos indígenas del país.

${ }^{17}$ Dirigido a funcionarios y funcionarias del Sistema de Justicia del Poder Judicial, la Defensa Pública del Ministerio de Justicia y Derechos Humanos, el Ministerio Público y la Policía Nacional del Perú. Cuenta con un proyecto piloto en el Distrito judicial de San Martín.

${ }^{18}$ Focaliza su atención en las mujeres indígenas, y está dirigido a: funcionarios del sistema de justicia responsables de la atención y orientación de las comunidades indígenas cuyo territorio se ubica dentro de la competencia de las Cortes Superiores de Ucayali y Loreto, así como a los funcionarios de primer contacto; Policía regional, funcionarios del Poder Judicial, la Defensa Pública y el Ministerio Público.

${ }^{19}$ El primero, está orientado a establecer los principios, pautas y estrategias que las autoridades de los sistemas de justicia, ordinarios y especiales, deben tener en cuenta al momento de relacionarse. Se basa en el diálogo en condiciones de igualdad, en cuanto guía de la coordinación y cooperación entre los diversos actores de la justicia intercultural. Busca superar la tendencia a la homogenización de las tradiciones jurídicas y la imposición del derecho positivo por sobre el derecho propio de los diversos pueblos del país. El segundo, pretende implementar la pertinencia cultural en el servicio que brinda el Poder Judicial a comuneros y ronderos cuando se encuentren inmersos en procesos ordinarios, estableciendo garantías relacionadas con los derechos culturales y lingüísticos, así como un conjunto de principios y reglas de comportamiento.
} 
En Bolivia encontramos el Protocolo de prevención, atención y sanción a toda forma de vulneración a la integridad sexual de niñas, niños y adolescentes, que:

... presenta un conjunto de procedimientos específicos que describen la forma cómo las entidades públicas, privadas, instituciones de la sociedad civil y la familia, con la participación de las niñas, niños y adolescentes, deben actuar para garantizar a las víctimas de violencia sexual la restitución de sus derechos. (Ministerio de Justicia y Transparencia Institucional, 2017, p. 24).

Por razones de extensión, no es posible hacer referencia en forma detallada a todos y cada uno de estos instrumentos, pero sí podemos establecer algunos comunes denominadores:

a) Todos los protocolos revisados dan cuenta de países que cuentan con reconocimiento constitucional a sus pueblos indígenas, mediante la consagración de sí mismos como Estados plurinacionales o pluriculturales. En ellos los pueblos indígenas se encuentran bien protegidos mediante la legislación interna y la ratificación de instrumentos internacionales sobre derechos de pueblos indígenas. Su reconocimiento incluye también el respeto y valor jurídico de sus prácticas, entre ellas la justicia e instituciones indígenas, donde también existe una prolífica experiencia en cuanto a la adecuación por parte de las agencias estatales, en especial de justicia, respecto a las formas en que deben dialogar con los pueblos indígenas. Este diálogo va desde formas de atención y tratamiento desde las agencias policiales, de justicia, y en general desde los agentes del Estado cuando se trata de la atención de miembros de pueblos indígenas en el contexto del ejercicio pleno de sus derechos.

b) En todos ellos, con mayor o menor profundidad, se consideran mecanismos de adecuación y de coordinación entre la justicia estatal y la de los pueblos indígenas con sus respectivas instituciones. México es uno de los ejemplos. Junto con reconocer a los Estados Unidos Mexicanos como un Estado Plurinacional (Constitución Política de los Estados Unidos Mexicanos, 2017, art. 2), que funda la base de la nación en la diversidad de diferentes pueblos indígenas que la integran, reconoce en estos a sujetos de derechos parte de colectivos con formas jurídicas e instituciones propias. Esto sin duda genera un marco legislativo bastante rico y que es común a todo el territorio de la federación. Así también, entre otros los estados de Chiapas, Tabasco, Oaxaca han generado dentro de su legislación interna mecanismos que reconocen estos derechos de los pueblos indígenas, y ordenan mediante leyes, decretos, auto acordados, instructivos de carácter legal, una serie de cuestiones relativas al trato de los agentes del Estado a miembros de pueblos indígenas. En ello se incluye la actuación que se debe tener al primer contacto, el uso de traductores, el reconocimiento a la jurisdicción propia, etc. Perú es otro de los países en el cual se han desarrollado protocolos nacionales y por distritos judiciales, 
tales como los de San Martin, Uyacali y Loreto. Además de considerar la legislación nacional del Perú y protocolos de actuación generales, los distritos mencionados tienen protocolos más específicos considerando las diferencias territoriales de los pueblos indígenas, por ejemplo, para pueblos andinos y para pueblos de las amazonas. Asimismo Guatemala, además de protocolos generales, tiene también protocolos específicos, como el de mujeres indígenas ${ }^{20}$.

c) Los protocolos estudiados se sustentan en el derecho internacional de los derechos humanos, enfatizando en los estándares sobre derechos indígenas y las Reglas de Brasilia sobre acceso a la Justicia en condición de vulnerabilidad (Secretaría Permanente de Cumbre Judicial Iberoamericana, 2008) ${ }^{21}$ de las personas en condición de vulnerabilidad, y han sido generados y difundidos desde lo más alto de la magistratura, sea la Corte Suprema o su equivalente (vid. supra).

d) La activación del procedimiento de atención específica a usuarios indígenas se satisface con la auto identificación, lo que debe suceder en el primer contacto de la autoridad (normalmente agentes policiales) con el usuario, momento en el cual debe activarse el protocolo. "La conciencia de su identidad..." (Convenio $\mathrm{N}^{\circ} 169,1991$, art. 1, no. 2) es un derecho intrínseco de los pueblos y personas indígenas (Pueblo Saramaka vs. Surinam, 2007, párr. 188), que no puede ser coartada por la atribución que el Estado pueda ejercer a través de su legislación o de sus órganos jurisdiccionales (Instituto Interamericano de Derechos Humanos, 2015, p. 18; Oficina Nacional de Justicia de Paz y Justicia Indígena del Poder Judicial, 2015, p. 86).

e) En cuanto a los derechos lingüísticos, todos los procedimientos o interacción en el ámbito judicial deben necesariamente realizarse en el idioma de la comunidad objeto del Protocolo, con el eventual auxilio de personas capacitadas que conozcan el idioma del pueblo indígena en cuestión (Prieto Giménez, 2017, p. 33; Consejo Ejecutivo del Poder Judicial, 2015, p. 28; Oficina Nacional de Justicia de Paz y Justicia Indígena del Poder Judicial, 2014, p. 31). No solamente se establece el derecho a un intérprete/traductor, sino la posibilidad de elegir entre alguna institución acreditada, pero también entre pueblos o comunidades indígenas, inclusive los miembros de la misma comunidad a la cual el usuario pertenece, bajo propuesta del mismo beneficiario del protocolo (Poder Judicial del Estado de Tabasco, 2014, p. 23; Oficina Nacional de Justicia de Paz y Justicia Indígena del Poder Judicial, 2015, p. 88). Además los funcionarios del poder judicial en lugares con alta concentración de pueblos indígenas, deben conocer el idioma y la cultura de la comunidad interesada, a través de cursos especializados, recurriendo al auxilio de un intérprete autori-

\footnotetext{
${ }^{20}$ Dirigido a personal profesional y técnico de la Unidad Jurídica de la Defensoría de Mujeres Indígenas de Guatemala.

${ }^{21}$ También conocidas como las "100 Reglas de Brasilia".
} 
zado cuando sea necesario (Instituto Interamericano de Derechos Humanos, 2015, pp. 36-37; véase también, Oficina Nacional de Justicia de Paz y Justicia Indígena del Poder Judicial, 2014, p. 53).

f) La mayoría de los protocolos hacen especial mención a mujeres, niños, niñas y adolescentes indígenas, en cuanto categorías aún más vulnerables, a raíz de la triple discriminación que sufren: por ser indígenas, por género o infancia, $y$, en la mayoría de los casos, por pertenecer a los estratos sociales mas bajos de la población (Espinel Gaona, 2016, pp. 18-19). En relación a los niños, niñas y adolescentes indígenas, se hace hincapié en la importancia de una atención prioritaria, especialmente en casos de violencia (Consejo Ejecutivo del Poder Judicial, 2015, p. 28), y acorde a los valores de su comunidad, siendo recomendable articular una estrecha y permanente comunicación con los representantes de aquella (Consejo Ejecutivo del Poder Judicial, 2015, p. 28). Cualquier acción o decisión que involucre a un niños, niñas y adolescentes indígenas debe contemplar el interés superior del niño, así como los principios de interculturalidad y protección especial (Espinel Gaona, 2016, pp. 17-18). En cuanto al enfoque de género, destaca el Manual de atención jurídica: área de atención integral de casos, desarrollado por la Defensoría de la Mujer Indígena (s.f.) de Guatemala, la preocupación general en otros protocolos por evitar todo tipo de conductas que puedan provocar una revictimización, por ejemplo, cualquier acto procesal que no sea estrictamente necesario (Oficina Nacional de Justicia de Paz y Justicia Indígena del Poder Judicial, 2015, p. 93), así como la necesidad de contar con funcionarios capacitados que puedan brindar una atención adecuada a las usuarias (Oficina Nacional de Justicia de Paz y Justicia Indígena del Poder Judicial, 2014, p. 56).

En todo caso, la forma en la que se entienden los derechos de los pueblos indígenas puede variar de una comunidad a otra, pues, "Por ejemplo, un mismo instituto, como el derecho a la identidad cultural, puede implicar prácticas muy distintas en diferentes universos culturales..." (Faundes Peñafiel y Le Bonniec, 2020, p. 173).

\section{Derecho chileno}

Chile ha suscrito y ratificado los tres instrumentos internacionales que obligan a los Estados a asegurar la protección y goce efectivo e igualitario de los derechos humanos de los Pueblos Indígenas y de sus libertades fundamentales: El Convenio № 169 (1991, art. 2 y 3); Declaración de Naciones Unidas sobre los Derechos de los Pueblos Indígenas (2007, art. 2); Declaración Americana sobre los Derechos de los Pueblos Indígenas (2016, arts. VII y XXXI). Son estándares internacionales aquellas normas de dichos instrumentos que regulan la relación de los pueblos indígenas con la justicia, particularmente el derecho de los pueblos indígenas a conservar sus costumbres e instituciones propias, y a ejercer sus propias formas de resolución de conflictos - 
Convenio No 169 (1991, art. 8, no, 2 y art. 9, no. 1); Declaración de Naciones Unidas sobre los Derechos de los Pueblos Indígenas (2007, art. 34); Declaración Americana sobre los Derechos de los Pueblos Indígenas (2016, art. XXII). Ello debe contrastarse con la sentencia del Tribunal Constitucional en esta materia (Requerimiento presentado por un grupo de Diputados respecto de la inconstitucionalidad del Convenio No 169, 2000, cons. 52 y 53)-; la consideración de las costumbres y del derecho consuetudinario al momento de aplicar la legislación nacional o al aplicar sanciones Convenio No 169 (1991, art. 8, no.1; art. 9, no. 2 y art. 10); Declaración de Naciones Unidas sobre los Derechos de los Pueblos Indígenas (2017, art 40); Declaración Americana sobre los Derechos de los Pueblos Indígenas (2016, art. XXXIV)-, así como el deber de implementar las medidas necesarias para asegurar que los miembros de pueblos indígenas puedan afrontar nuevas condiciones de vida, poder entender y darse a entender en actuaciones políticas, jurídicas y administrativas, debiendo proporcionarles servicios de interpretación u otros medios adecuados para estos efectos (Convenio No 169, 19912, art. 5, c; Declaración de Naciones Unidas sobre los Derechos de los Pueblos Indígenas, 2007, art. 13, no. 2; Declaración Americana sobre los Derechos de los Pueblos Indígenas, 2016, art. XIII).

Sin embargo, no se reconocen constitucionalmente, lo que no obsta a que, en cuanto "individuos", los indígenas gocen de manera igualitaria de los derechos que se reconocen en la Carta Fundamental respecto de todas las personas, siendo de especial importancia el derecho a "La igualdad ante la ley" (Constitución Política de la República de Chile, 2005, art. 19, no. 2) y a la igual protección en el ejercicio de los derechos (Constitución Política de la República de Chile, 2005, art. 19, no. 3) además de los derechos procesales y procesales penales (Constitución Política de la República de Chile, 2005, art. 19, no. 7). Ahora bien, existe un reconocimiento legal específico de los mismos a través de la Ley № 19.253 (1993), que establece normas sobre protección, fomento y desarrollo de los indígenas y, además, crea la Corporación Nacional de Desarrollo Indígena (CONADI). Este cuerpo legal reitera la obligación del Estado de "...respetar, proteger y promover el desarrollo de los indígenas, sus culturas, familias y comunidades..." (Ley $N^{\circ} 19.253,1993$, art. 1, inc. 3) para lo cual se deben adoptar las medidas adecuadas, aunque su formulación no ha estado exenta de críticas (Aylwin Oyarzún, Guerra Schleef, Silva Neriz, y Yáñez Fuenzalida, 2017, pp. 258259). El texto legislativo no abarcó materias planteadas inicialmente en su anteproyecto, tales como el concepto de territorialidad indígena el derecho a no ser trasladado de sus tierras o por lo menos ser previamente consultados antes de que eso ocurriera, y el reconocimiento de derechos preferentes en cuanto a manejo de recursos naturales. (Aylwin Oyarzún, 2002, p. 15).

En relación a los derechos lingüísticos, dispone que "El reconocimiento, respeto y protección de las culturas e idiomas indígenas contemplará [...] El uso y conservación de los mismos en las áreas de alta densidad indígena" (Ley № 19.253, 1993, art. 28 , a). Conjuntamente, en el ámbito de los procesos judiciales señala que 
El juez encargado del conocimiento de una causa indígena, a solicitud de parte interesada y en actuaciones o diligencias en que se requiera la presencia personal del indígena, deberá aceptar el uso de la lengua materna debiendo al efecto hacerse asesorar por traductor idóneo, el que será proporcionado por la Corporación [Nacional Indígena]. (Ley $\mathrm{N}^{\circ} 19.253$, 1993 , art. 54, inc. 3)

Específicamente en lo que respecta a los derechos lingüísticos, tanto el Código Procesal Penal (2000, art. 291) como el Código de Procedimiento Civil (1902, art. 382, incs. 1 y 2) contemplan el derecho a ser asistido por un intérprete, sin circunscribirlo únicamente a personas indígenas.

En lo que se refiere a la relación de los indígenas con la justicia, dispone que sus costumbres constituirán derecho, siempre que no contravengan lo dispuesto en la Constitución y las leyes. En materia penal, se reconoce que estas podrían configurar el presupuesto de alguna causal atenuante o eximente de responsabilidad penal (Ley $\mathrm{N}^{\circ} 19.253,1993$, art. 54, inc. 1). No hay reconocimiento al derecho propio, y pese a la existencia de algunos sistemas de justicia indígena de resolución de conflictos sobre este punto véase; Villegas Díaz y Mella-Seguel (2017). Sobre el Az Mapu en el pueblo mapuche, véas; Melin Pehuen, Coliqueo Collipal, Curihuinca Neira y Royo Letelier (2016, p. 34)-, son inválidos ante el sistema oficial. Solo en ocasiones se "adapta" el derecho propio a las categorías jurídicas de la legislación oficial, siendo esto obligatorio conforme a los estándares internacionales (Couso Salas, 2013, p. 205). Por ello, y a pesar de que la ratificación del Convenio № 169 (1991) instan por el reconocimiento de una justicia no oficial (la indígena), es posible afirmar que el sistema judicial chileno es "...monista, monocultural y eurocéntrico" (Melin Pehuen et al, 2016, p. 45).

En cuanto grupo que históricamente ha sufrido marginación y discriminación, los indígenas se encuentran amparados también por la Ley $N^{\circ} 20.609$ (2012) que establece medidas contra la discriminación (críticamente sobre la ley; Gauché Marchetti, 2014, pp. 40, 41 y 48). Dicha ley, tuvo como propósito instaurar un mecanismo judicial que permita restablecer eficazmente el imperio del Derecho toda vez que se cometa un acto de discriminación arbitraria. Define como tal a

...toda distinción, exclusión o restricción que carezca de justificación razonable, efectuada por agentes del Estado o particulares, y que cause privación, perturbación o amenaza en el ejercicio legítimo de los derechos fundamentales [...], en particular cuando se funden en motivos tales como la raza o etnia [entre otros]... (Ley $\mathrm{N}^{\circ} 20.609,2012$, art. 2, inc. 1).

En el ámbito judicial, la Corte Suprema, suscribió en 2014 el Protocolo lberoamericano de actuación judicial: para mejorar el acceso a la justicia de personas con discapacidad, migrantes, niñas, niños, adolescentes, comunidades y pueblos indígenas (Suprema Corte de Justicia de la Nación, 2014) instrumento que vino a sumarse al Protocolos de aten- 
ción: modelo de atención de usuarios del Poder Judicial, de Diciembre de 2010, sin embargo ambos instrumentos establecen sólo directrices y principios generales en los cuales debe basarse la atención, sin ahondar en cuestiones centrales y más específicas tales como aspectos propios de los derechos indígenas, mediadores lingüísticos y culturales, especialización de funcionarios administrativos y jueces.

Por iniciativa de la Defensoría Penal Pública, se crea un Protocolo de atención a mujeres indígenas extranjeras privadas de libertad. Una guía bastante completa desarrollada por Lara Escalona y Hernández Badilla (2015) que orienta la labor de sus funcionarios en orden a los pasos a seguir y aspectos que se deben tener presente en casos de imputadas o condenadas indígenas extranjeras, privadas de libertad, que va desde el primer contacto con la imputada hasta el fin del procedimiento. Su objetivo es mejorar las condiciones de reclusión y acceso a la justicia de las mujeres indígenas extranjeras privadas de libertad en las regiones del norte grande del país, donde existe un fuerte componente indígena aymara (Lara Escalona y Hernández Badilla, 2015). Este protocolo señala expresamente lo relevante que es identificar a tiempo a este tipo de usuarias. Dicha tarea queda a cargo del/la facilitador/a intercultural, preferentemente al tomar conocimiento del listado de detenidos que sea proporcionado por el respectivo Juzgado de Garantía o por el Ministerio Público. El criterio para determinar si se trata de una imputada indígena extranjera, consiste en la constatación de los apellidos. Si el/la facilitador/a reconoce a una usuaria de este tipo debe dar inmediato aviso al defensor para concurrir juntos a la primera entrevista privada, la que, de preferencia debería ocurrir en el recinto policial en la cual se encuentre detenida (Lara Escalona y Hernández Badilla, 2015, p. 36). El protocolo destaca la forma en la que debería realizarse esta primera entrevista considerando "...los aspectos culturales diferenciadores de su defendida..." (Lara Escalona y Hernández Badilla, 2015, p. 35), por lo que debe destinarse un mayor tiempo del habitual, usar un lenguaje claro y pausado, y la asesoría de intérprete si es necesario. Debe ponerse atención en todo lo que la usuaria quisiera hacer presente. Esto ayuda a forjar una relación de confianza entre defensor y defendida. Otros aspectos que se consideran necesarios en la primera entrevista son el presentar al defensor/a y al facilitador/a intercultural y explicar el rol que estos cumplirán; dar a conocer los derechos de la detenida; e, informar sobre el derecho a dar aviso consular (Convención de Viena sobre Relaciones Consulares, 1967, art. 36, b).

También en el ámbito de la defensa penal pública destaca ya desde antes de 2010 el Modelo de Defensa Penal para imputados indígenas (Defensoría Penal Pública, 2010), en cumplimiento a las directrices señaladas por el Defensor Nacional en el Oficio No 177/2003 y al modelo La defensa de imputados indígenas en la Defensoría Penal Pública (Defensoría Penal Pública, 2008). Este Modelo de Defensa especializada surge como consecuencia directa de la creación en el año 2001, de la Defensoría Penal Mapuche en la ciudad de Temuco y su posterior formalización en el año 2003. En este modelo se contemplan criterios para determinar si se está frente a un imputado y/o 
causa indígena, además de desarrollar una serie de antecedentes tanto históricos, sociales y jurídicos que pretenden servir de fundamento para un adecuado trato a esta categoría de usuarios y, también, para la elaboración de teorías del caso que contemplen los aspectos socioculturales de los imputados.

\section{1. ¿Deber de Consulta para un protocolo de actuación ante tribunales?}

Conforme al Convenio № 169 (1991, art. 6) de la Organización Internacional del Trabajo, la Declaración de Naciones Unidas sobre los Derechos de los Pueblos Indígenas (2007, art. 19) y la Declaración Americana sobre los Derechos de los Pueblos Indígenas (2016, art. XXIII), el Estado de Chile tiene el deber de consultar a los pueblos indígenas, incluidos niños, niñas y adolescentes indígenas (Observación General № 11 , 2009), cada vez que se promuevan medidas legales o administrativas susceptibles de afectarles directamente, a fin de obtener su consentimiento libre, previo e informado (Anaya, 2009b, párr. 10). De esta forma, adquiriendo el protocolo el carácter de una medida administrativa y susceptible de ser contenido en una norma jurídica, que afecta directamente a los pueblos indígenas debe ser sometido a un proceso de consulta de conformidad con los estándares internacionales de derechos humanos. Dos cuestiones deben resolverse, la primera, el contenido de la "afectación" al pueblo originario, la segunda, el por qué la consulta debe realizarse conforme a los estándares internacionales.

En cuanto a lo primero, el protocolo de atención a usuarios indígenas establece ciertas orientaciones, criterios, procedimientos y fases de atención, que guiarán las relaciones entre personas pertenecientes a pueblos indígenas y el municipio así como la judicatura, tendientes a respetar los derechos colectivos e individuales de las personas pertenecientes a pueblos indígenas. Entre ellos los derechos de igualdad y a no ser discriminados, a conservar sus usos y costumbres, así como sus instituciones, cuando sean compatibles con los derechos humanos, de acceso a la justicia y a la tutela judicial efectiva con pertinencia indígena, y a tener un intérprete en los procesos judiciales, entre otros. En este sentido, el protocolo sería una manera de materializar en parte el deber del Estado de adoptar medidas específicas para concretar la igualdad ante la ley de los pueblos indígenas e impedir la discriminación por razones culturales.

En cuanto a lo segundo, la Corte Interamericana de Derechos Humanos ha sido enfática en destacar que la obligación de consultar a las "Comunidades y Pueblos Indígenas y Tribales" -analizando la situación considerando su realidad de facto (caracterizada principalmente por un estatus de pobreza y discriminación constante), así como su identidad cultural. A propósito de las "particularidades culturales" de los integrantes de las comunidades, Nash Rojas, Núñez Donald, y Bustamante Soldevilla (2014, pp. 13-14) citan el párrafo 213 de sentencia Caso Comunidad indígena Yakye Axa Vs. Paraguay del 17 de junio de 2005- y la obligación de asegurar su participa- 
ción en asuntos que les interesen, proviene de la obligación general, de acuerdo a la Convención Americana sobre Derechos Humanos (1978, art. 1, no. 1) “...de organizar adecuadamente todo el aparato gubernamental [...] de manera tal que sean capaces de asegurar jurídicamente el libre y pleno ejercicio de los derechos..." (Pueblo Indígena Kichwa de Sarayaku Vs. Ecuador, 2012, párr. 166).

La consulta previa implica que debe ser efectuada en las primeras etapas de las medidas a adoptar para recoger la opinión de la comunidad y así poder desechar la medida o posibilitar la adecuación de los planes y propuestas relativos a lo consultado. Que sea una consulta libre significa que se desarrolle en un clima de confianza mutua, sin la coerción de los agentes del Estado (Pueblo Indígena Kichwa de Sarayaku Vs. Ecuador, 2012, párr. 186). Asimismo, la(s) comunidad(es) deben haber recibido una información completa, veraz, transparente y verificable sobre la medida a consultar, para que puedan plantear sus dudas y evaluar beneficios y riesgos -sobre estos requisitos véase: Anaya, (2009b, párr. 53); y Pueblo Indígena Kichwa de Sarayaku Vs. Ecuador (2012, párr. 208)-. Una consulta hecha de buena fe implica que exista diálogo y que ambas partes participen activamente, sin que el Estado ejecute prácticas desintegradoras de la comunidad o fomente liderazgos paralelos (Pueblo Indígena Kichwa de Sarayaku Vs. Ecuador, 2012, párr. 186). Finalmente, una consulta pertinente culturalmente, implica que ella debe realizarse considerando las formas de organización política de la comunidad y procedimientos adecuados a aquella (Pueblo Indígena Kichwa de Sarayaku Vs. Ecuador, 2012, párr. 202). Esto implica que los representantes deben haber sido escogidos conforme a sus costumbres o tradiciones, y si se tratare de una comunidad urbana, elegidos de acuerdo a la forma que la organización haya decidido. Deben adoptarse todas las medidas tendientes a que los miembros de la(s) comunidad(es) no solo conozcan, sino que comprendan lo que se está consultando, y que a su vez puedan darse a entender. En este sentido, y de ser necesario, deben facilitarse intérpretes $u$ otros medios para cumplir con ese objetivo (Pueblo Indígena Kichwa de Sarayaku Vs. Ecuador, 2012, párr. 201). La forma a través de la cual se toman las decisiones respecto de lo consultado debe considerar los mecanismos tradicionales de la comunidad para la toma de decisiones y debe darse el tiempo apropiado para que la comunidad pueda analizar y debatir la medida según la complejidad que ella tenga (Mecanismo de expertos sobre los derechos de los pueblos indígenas, 2012, párrs. 14, 16 y 19).

Nuestro ordenamiento jurídico nacional, si bien ha ratificado el Convenio № 169 (1991) Organización Internacional del Trabajo, ha reglamentado el derecho de consulta mediante el Decreto No 66 (2014), norma que ha sido cuestionada fuertemente. Este decreto reconoce que "La consulta es un deber de los órganos de la Administración del Estado y un derecho de los pueblos indígenas susceptibles de ser afectados directamente..." (Decreto $N^{\circ} 66,2014$, art. 2). El concepto de "afectación directa" a que alude el Decreto $N^{\circ} 66$ (2014, art. 7, inc. 6) restringe considerablemente el derecho a consulta consagrado en el Convenio № 169 (1991) de la Organización 
Internacional del Trabajo, dado que lo limita a casos en los que la medida cause un impacto significativo. Si ella no causa una afectación directa o significativa, conforme a la legislación nacional, ésta no debería ser consultada, lo que ha sido objetado a la luz de los estándares internacionales de derechos humanos a los que el Estado chileno se ha comprometido (Barros van Hövell y Schönsteiner, 2014, pp. 217-220). Recordamos que el Comité de Derechos Humanos de Naciones Unidas en su último informe respecto al Estado de Chile, manifestó su preocupación por haber denotado que

...los pueblos indígenas no sean consultados previamente en el proceso de adopción de decisiones respecto de cuestiones que afectan a sus derechos y que todavía no se haya establecido un mecanismo efectivo de consulta y participación indígena, de acuerdo a las normas internacionales. (Observaciones finales sobre el sexto informe periódico de Chile, 2014, párr. 10)

El Estado de Chile frente a esta controversia normativa ha actuado en forma ambivalente. Por un lado la Contraloría General de la República cada vez que se ha pronunciado sobre el deber de consulta -véase: Dictamen $N^{\circ} 597$ (Vivienda y Urbanismo, planes reguladores o planos reguladores, 2018); Dictamen $N^{\circ} 44051$ (Plan Regulador Comunal de Chile Chico, 2017); Dictamen N 30349 (Vivienda y urbanismo, planes reguladores o planos reguladores, consulta indígena, 2016); Dictamen № 40374 (Vivienda y urbanismo, planes reguladores, 2015); Dictamen $N^{\circ} 31587$ (Planes reguladores, 2015)- lo ha hecho en referencia a la legislación nacional, y en sentido negativo respecto de aquellas medidas que fueron adoptadas sin ser consultadas, pero en referencia explícita al Decreto $N^{\circ} 66$ (2014). Incluso en un caso en el que el proceso de consulta cumplió con los estándares de derechos humanos y se realizó de conformidad con los tratados internacionales, fue objetado por la Contraloría General de la República (Consulta indígena, atención de salud, pertinencia cultural, 2016) porque el procedimiento no se ajustó al reglamento establecido en dicho decreto sino directamente a lo indicado por el Convenio Nº 169 (1991) de la Organización Internacional del Trabajo (Centro de Derechos Humanos y Servicio de Salud Metropolitano Oriente, 2016).

Pero por otro lado, el Estado ha ido también tomando conciencia del incumplimiento de estos estándares que el Decreto importa, y también han existido procesos exitosos de consulta indígena, cuyo procedimiento fue consensuado con las comunidades, al margen del Decreto $N^{\circ} 66$ (2014), y en aplicación del tratado internacional, tales como los procesos de consulta respecto del Ministerio de la Cultura (Consejo Nacional de la Cultura y las Artes, 2016), y los del Ministerio de Obras Públicas. Véase el Listado de Iniciativas Consulta Indígena en el sitio de Asuntos Indígenas (s.f.) de dicho Ministerio. 


\subsection{Para un protocolo de atención a usuarios indígenas en Juzgados de Policía Local}

Para aterrizar lo expuesto a una realidad concreta se han escogido los Juzgados de Policía Local, pensando que en Araucanía ellos reciben gran afluencia de usuarios indígenas (Equipo FONDEF ID 16110424, s.f.; Sobre el trabajo etnogáfico que lo sustenta, ampliamente Martínez Cañoles, 2019). En cuanto a su contenido éste debería considerar los comunes denominadores antes señalados de las legislaciones examinadas (ampliamente en Le Bonniec et al., 2019), siendo conveniente examinar cual podría ser su naturaleza jurídica. Es una medida de carácter administrativo que podría ser recogida mediante un reglamento municipal -de conformidad con el Decreto con Fuerza de Ley $\mathrm{N}^{\circ} 1(2006 \text {, art. 12) })^{22}$ - por su alcance y obligatoriedad, pero asimismo en un oficio.

En este punto hay que considerar la naturaleza híbrida de los Juzgados de Policía Local en cuanto su personal es dependiente de las municipalidades, con la sola excepción de los jueces, que, por expresa disposición del Decreto № 307 (1978) son "....independientes de la autoridad municipal en el desempeño de sus funciones..." Decreto № 307 (1978, art. 8, inc. 1), y están “...sujetos a la supervigilancia directiva, correccional y económica de la respectiva Corte de Apelaciones" Decreto $\mathrm{N}^{\circ}$ 307 (1978, art. 8, inc. 2). En este sentido, y para que no solo los funcionarios sino también jueces pudiesen quedar obligados por dicho protocolo y afectos a sanción por su incumplimiento, idealmente debería contenerse en una instrucción o un auto acordado de la Corte de Apelaciones de la cual dependen, o bien en un auto acordado más general emanado de la Corte Suprema, ambas en ejercicio de sus atribuciones de conformidad con la Constitución Política de la República de Chile (2005) "La Corte Suprema tiene la superintendencia directiva, correccional y económica de todos los tribunales de la Nación" (art. 82, inc. 1) y el Código Orgánico de Tribunales "Corresponderá a todo el tribunal el ejercicio de las facultades disciplinarias, administrativas y económicas, sin perjuicio de que las salas puedan ejercer las primeras en los casos de los artículos 542 y 543 en los asuntos que estén conociendo" (Ley № 7421, 1943 , art. 66, inc. 4).

De todas formas, si fuese contenido en un reglamento municipal, al ser una norma que forma parte del ordenamiento jurídico del municipio en el cual el juez ejerce funciones, existe un deber de cumplimiento del instrumento. Así lo corrobora el Dictamen № 6962 de 29 de febrero de 2000 de la Contraloría General de la República.

\footnotetext{
${ }^{22}$ Que señala que las resoluciones que adopten las municipalidades pueden ser ordenanzas (normas generales y obligatorias aplicables a la comunidad, ej. establecimiento de multas), reglamentos municipales (normas generales obligatorias y permanentes, relativas a materias de orden interno de la municipalidad), decretos alcaldicios (resoluciones que versan sobre casos particulares) o instrucciones (directivas impartidas a los subalternos).
} 
... los empleados de los Juzgados de Policía Local, incluido el juez, son funcionarios municipales regidos por la normativa aplicable a ese personal, específicamente la Ley $\mathrm{N}^{\circ} \mathbf{1 8 . 8 8 3}$, de la que se exceptúan los jueces en aspectos como ingresos, calificaciones y aplicación de medidas disciplinarias, porque están sujetos a la supervigilancia directiva, correccional y económica de la Corte de Apelaciones correspondiente (aplica dictamen $\mathrm{N}^{\circ} 31.399$ de 1993).

Precisado lo anterior, cabe puntualizar que al Juez de Policía Local le son plenamente aplicables las disposiciones del párrafo $4^{\circ}$, Título IV de la Ley $\mathrm{N}^{\circ} 18.883$, relativas a permisos, licencias y feriados, por lo tanto, no procedió que el recurrente se ausentara del Juzgado los días 5, 6 y 7 de mayo de 1999, para asistir al "Cuarto Congreso Nacional de la Asociación Chilena de Municipalidades", sin haber, previamente, solicitado y obtenido, por parte de la Alcaldesa, el permiso a que alude el artículo 108 de la citada Ley $N^{\circ} 18.883$.

Ahora, la situación antes descrita, sin embargo, no ameritaba la instrucción de un sumario administrativo en su contra, toda vez que conforme lo dispone el artículo $8^{\circ}$ de la Ley $N^{\circ} 15.231$, los Jueces de Policía Local, en cuanto al desempeño como tales, son independientes de toda autoridad municipal; duran, en principio, indefinidamente en sus funciones y no pueden ser removidos ni separados por la Municipalidad y están directamente sujetos a la supervigilancia directiva, correccional y económica de la respectiva Corte de Apelaciones. (Juez policía local ausencias descuentos, 2000, párrs. 6, 7 y 8 )

No obstante este deber jurídico no podría tener aparejada una sanción disciplinaria para el juez que lo incumpliere. No podría contemplarse ni en el reglamento mismo que contuviere el protocolo, ni tampoco desprenderse de la aplicación de la Ley $N^{\circ} 18.883$ (1989, art. 31, inc. 1) que fija el Estatuto Administrativo para funcionarios Municipales, pues los jueces quedan exceptuados de materias tales como la sujeción a un proceso de calificación efectuado por el superior jerárquico municipal y la aplicación de medidas disciplinarias por parte de dicha autoridad. Así, las conductas que éstos ejecutaren en su investidura como juez, quedan bajo la súper vigilancia de la Corte de Apelaciones respectiva, así como a la Corte Suprema.

En efecto, la Corte de Apelaciones, es la autoridad llamada a perseguir la eventual responsabilidad del Juez de Policía Local por las irregularidades en que éste hubiere incurrido, con ocasión de su desempeño como tal, correspondiendo a dicho Tribunal, una vez que las irregularidades han sido puestas en su conocimiento por la autoridad alcaldicia, pronunciarse al respecto y aplicar, si lo estima pertinente, la correspondiente medida disciplinaria (aplica criterio contenido en los dictámenes $\mathrm{N}^{\circ}$ s. 57.339, de 1975 y 4.840 de 1991) (Juez policía local ausencias descuentos, 2000, párr. 9). 
Ergo, un protocolo de actuación ante Juzgados de Policía Local puede estar contenido en un reglamento municipal, pero idealmente debería existir una articulación con la Corte de Apelaciones respectiva, para que ésta diere una instrucción de cumplimiento del mismo al Juez de Policía Local.

\section{Conclusiones}

La necesidad de implementar un protocolo con pertinencia cultural a usuarios indígenas en tribunales de justicia encuentra su fundamento en normas contenidas en tratados internacionales de Derechos Humanos ratificados por Chile. Un protocolo de atención sería una medida de actuación positiva, concreta y necesaria para evitar conductas discriminatorias hacia indígenas.

Como se puede apreciar del análisis comparado, en las Constituciones citadas se reconoce en mayor o menor medida, a los pueblos indígenas, bajo distintas fórmulas, ya sea considerándose a sí mismos como Estados plurinacionales (Bolivia y Ecuador) o pluriculturales (México, Guatemala, Nicaragua, Colombia, Paraguay, Perú), incluida la referencia expresa a pueblos indígenas. También, en gran parte de ellas se reconoce expresamente el derecho de los pueblos indígenas a aplicar sus sistemas de justicia propios dentro de los territorios que ocupan.

En las legislaciones de México, Colombia, Ecuador, Paraguay, Perú y Bolivia la jurisdicción indígena tiene la misma jerarquía que la jurisdicción ordinaria, estableciéndose medidas de coordinación y de apoyo entre ambas, las que incluyen a sus órganos auxiliares. El sometimiento a la jurisdicción indígena es voluntario para el sujeto en todos ellos con excepción de México, sin perjuicio de la posibilidad de revisión ante la justicia ordinaria de casos resueltos en la comunidad cuando el afectado lo solicitare.

El aspecto que aparece más desarrollado en las legislaciones examinadas y que dice relación con la normativa que sirve de sustento a un protocolo de atención a usuarios, es el de los derechos lingüísticos. En todos se garantiza, al menos a nivel legal, el derecho a ser asistido por intérpretes. Ordenamientos jurídicos como el mexicano, el colombiano, ecuatoriano, paraguayo, peruano y el boliviano van un poco más allá, consagrando este derecho a nivel constitucional. Se reconocen como idiomas oficiales el castellano y las lenguas originarias (en los lugares donde se empleen), asegurando así el derecho de los indígenas a utilizar su propia lengua ante cualquier servicio público. Otros derechos que emanan de la ley son por ejemplo, no solo el derecho a ser atendido en su propia lengua, sino además que el juicio se sustancie en la lengua originaria, y que sea escrito en ambos idiomas (castellano e indígena). En algunos casos se exige también para poder ser juez en ciertos lugares, el tener conocimiento del idioma indígena ocupado en esa zona. Llama la atención también que 
en varios de estos países se han creado leyes específicas referentes a derechos lingüísticos, como es el caso de México, Guatemala, Colombia y Perú.

Como forma de hacer frente a la discriminación, en México y Bolivia hay leyes especiales que contemplan como medidas de nivelación o preventivas el capacitar a jueces y funcionarios del poder judicial en aspectos relativos a derechos, costumbres y jurisdicción indígena. Es preciso destacar que sólo en Bolivia se encontró una norma que hace especial alusión a la necesidad de implementar procedimientos y protocolos de atención a poblaciones específicas, como medida preventiva en contra de la discriminación.

En cuanto a los protocolos de atención a usuarios de tribunales, hay países que tienen protocolos generales (Nicaragua, Colombia, Ecuador, Paraguay), y otros en los que además de protocolos generales los tienen también específicos, ya sea en función del territorio o de categorías tales como el género (México, Perú, Guatemala) y otros que tienen solo alguno específico (Honduras). La mayoría de ellos emana desde las más altas autoridades, especialmente en la magistratura, y enfatizan en la necesidad de contar con mecanismos de coordinación entre la justicia estatal y la de los pueblos indígenas.

Para que se activen estos protocolos se sigue el criterio de la auto identificación del indígena, y se enfatiza en los derechos lingüísticos como ya se indicó.

La normativa chilena contempla algunas disposiciones importantes, sin embargo, tiende a restringir los derechos contemplados en los instrumentos internacionales enunciados, como sucede con el derecho a consulta o con el derecho de los pueblos indígenas a conservar sus instituciones y sus formas propias de resolución de conflictos.

La Defensoría Penal Pública ha sido el principal ente del Estado que, en el ámbito de la justicia, ha creado e implementado modelos de atención con pertinencia cultural para sus usuarios. Sin embargo, esto es prerrogativa y loable esfuerzo particular de este organismo en cuanto a la delimitación de sus actuaciones en materia de defensa especializada y se refiere solo a los procedimientos. En este sentido si bien en Chile se cuenta con una defensoría especializada para indígenas, el marco legal no los reconoce propiamente tal como colectivos de derechos con sus especificidades culturales, ni menos sus instituciones. El Poder Judicial, por su parte, ha suscrito protocolos de atención, sin embargo, estos no contemplan aspectos culturales específicos de los usuarios indígenas, sino que más bien contienen directrices y principios generales.

Un protocolo de actuación que pudiese implementar el Poder Judicial en Chile debe considerar la realidad jurídica marcada por la ausencia de reconocimiento constitucional, así como la ausencia de reconocimiento a la justicia indígena como 
tal. Sin embargo, es posible avanzar en algún tipo de guía práctica que considere los estándares internacionales de Derechos Humanos, concretamente el Convenio № 169 (1991) de la Organización Internacional del Trabajo, que forma parte del bloque de constitucionalidad de derechos que asiste a todos los ciudadanos.

\section{Reconocimientos}

Este trabajo forma parte de la investigación llevada a cabo en el proyecto del Fondo de Fomento al Desarrollo Científico y Tecnológico (FONDEF) / III Concurso IDeA en Dos Etapas 2016 "Protocolo de atención a Usuarios y Usuarias mapuche en tribunales de la Microrregión del Sur" (ID 16110424).

\section{Referencias Bibliográficas}

Aguilar Cavallo, G., Lafosse, S., Rojas Corral, H. y Steward, R. (2010). The constitutional recognition of Indigenous Peoples in Latin America. Pace international law review (Online), 2(2), pp. 44-96. Recuperado de https://bit.ly/3gx3V4O

Anaya, J. (2009a). Indigenous peoples and the international system. En su International Human Rights and Indigenous Peoples (pp. 37-54). Austin, TX: Wolters Kluwer.

Anaya, J. (2009b, Octubre 5). La situación de los pueblos indígenas en Chile: seguimiento a las recomendaciones hechas por el Relator Especial anterior. Informe del Relator Especial sobre la situación de los derechos humanos y las libertades fundamentales de los indígenas (Informe no. A/HRC/12/34/Add.6). Consejo de Derechos Humanos - Asamblea General - Naciones Unidas [Archivo PDF]. Recuperado de https://bit.ly/2VIJ7pY

Atala Riffo y Niñas Vs. Chile, Sentencia Serie C N 239 (Corte Interamericana de Derechos Humanos 24 de febrero de 2012). Recuperado de https://bit.ly/3clC5kX

Aylwin Oyarzún, J. (2002, Mayo). Política pública y pueblos indígenas: el caso de la política de tierras del Estado chileno y el pueblo mapuche (Working paper). Recuperado de https://bit.ly/3glel38

Aylwin Oyarzún, J., Guerra Schleef, F., Silva Neriz, H., y Yáñez Fuenzalida, N . (2017). Chile. The indigenous world (Online), 2017, 252-265. Recuperado de https://bit.ly/3xqwCac

Barros van Hövell, A. y Schönsteiner, J. (2014). Diligencia debida, proyectos de inversión, propiedad sobre los recursos naturales y consulta libre, previa e informada a los pueblos indígenas y comunidades indígenas concernidas. En T. Vial Solar, (Ed.). Informe anual sobre derechos humanos en Chile 2014 (pp. 203-244). Santiago: Universidad Diego Portales. Recuperado de https://bit.ly/3xjuAss 
Birgin, H. y Kohen, B. (2006). El acceso a la justicia como derecho. En su Acceso a la Justicia como garantía de igualdad. Instituciones, actores y experiencias comparadas (pp. 15-26). Buenos Aires: Biblos.

Botero Marino, C. (2008). Los retos del juez constitucional en un Estado multicultural: el caso de Colombia. En: L. Giraudo (Ed.), Derechos, costumbres y jurisdicciones indígenas en la América Latina contemporánea (pp. 145-184). Madrid: Centro de Estudios Políticos y Constitucionales.

del Castillo Pinto, L. (2008). Perú: entre la jurisdicción especial de las comunidades y la unidad del poder judicial. En L. Giraudo (Ed.), Derechos, costumbres y jurisdicciones indígenas en la América Latina contemporánea (pp. 243-264). Madrid: Centro de Estudios Políticos y Constitucionales.

Centro de Derechos Humanos, y Servicio de Salud Metropolitano Oriente. (2016). Proceso de consulta reglamento de salud intercultural (Informe observación.). Santiago: Universidad de Chile.

Código de Procedimiento Civil. Suplemento del Registro Oficial №58, Quito, Ecuador, 12 de julio de 2005. Recuperado de https://bit.ly/3qZ9TzY

Código de Procedimiento Penal. Suplemento del Registro Oficial N. 360, Quito, Ecuador, 13 de enero de 2000. Recuperado de https://bit.ly/3k3av6b

Código Federal de Procedimientos Civiles. Diario Oficial de la Federación, México, 24 de febrero de 1943. Recuperado de https://bit.ly/3hVulZk

Código Nacional de Procedimientos Penales. Diario Oficial de la Federación, México, 5 de marzo de 2014. Recuperado de https://bit.ly/36so8Us

Código Orgánico de la Función Judicial. Suplemento del Registro Oficial No. 544, Quito, Ecuador, 9 de marzo 2009. Recuperado de https://bit.ly/3dWH567

Código Penal Federal. Diario Oficial de la Federación, México, 14 de agosto de 1931. Recuperado de https://bit.ly/3jW7Ifg

Consejo Ejecutivo del Poder Judicial. (2015). Protocolo de Atención y Orientación Legal con Enfoque Intercultural. Dirigido a funcionarios del Sistema Estatal de Justicia. Recuperado de https://bit.ly/3k2xGOk

Consejo Nacional de la Cultura y las Artes. (2016). Diálogo de las culturas: sistematización del proceso de consulta previa a los Pueblos Indígenas para la creación del Ministerio de las Culturas, las Artes y el Patrimonio. Santiago: CNCA. Recuperado de https://bit.ly/3pVCy8E 
Bases normativas para un protocolo de atención a usuarios indígenas...

Consulta indígena, atención de salud, pertinencia cultural, Dictamen N 39884 (Contraloría General de la República 30 de mayo de 2016). Recuperado de https://bit.ly/3vBNjOx

Constitución de la República del Ecuador. Registro Oficial No. 449, Quito, Ecuador, 20 de octubre de 2008. Recuperado de https://bit.ly/2SZdFMW

Constitución de la República de Honduras. La Gaceta, Tegucigalpa, Honduras, 11 de enero 1982. Recuperado de https://bit.ly/3jYgf1o

Constitución de la República del Paraguay. Asunción, Paraguay, 20 de junio de 1992. Recuperado de https://bit.ly/36ojQxC

Constitución Política de la República de Chile. Diario Oficial de la República de Chile, Santiago, Chile, 22 de septiembre de 2005. Recuperado de http://bcn.cl/1uva9

Constitución Política de la República de Colombia. Gaceta Constitucional, Bogotá, Colombia, 20 de julio de 1991. Recuperado de https://bit.ly/3hRA7jJ

Constitución Política de la República de Guatemala. Asamblea Nacional Constituyente, Ciudad de Guatemala, Guatemala, 31 de mayo 1985. Recuperado de https://bit.ly/3ws9Dus

Constitución Política de la República de Nicaragua. Texto íntegro con reformas incorporadas a 2014. La Gaceta, Diario Oficial, Managua, Nicaragua, 18 de febrero de 2014. Recuperado de https://bit.ly/3wsu5eG

Constitución Política de los Estados Unidos Mexicanos. Diario Oficial de la Federación, México, 5 de febrero de 1917. Recuperado de https://bit.ly/3hNXdle

Constitución Política del Estado plurinacional de Bolivia. Gaceta Oficial del Estado Plurinacional de Bolivia, La Paz, Bolivia, 7 de febrero de 2009, Recuperado de https://bit.ly/34KOyjl

Constitución Política del Perú. El Peruano, Diario Oficial, Lima, Perú, 31 de diciembre de 1993. Recuperado de https://bit.ly/36nOnvC

Convención Americana sobre Derechos Humanos (Pacto de San José). Organización de los Estados Americanos, San José, Costa Rica, 18 de julio de 1978. Recuperado de https://bit.ly/3ogz53i

Convención de Viena sobre Relaciones Consulares. Organización de las Naciones Unidas, 19 de marzo de 1967. Recuperado de https://bit.ly/3qYeKli

Convención Interamericana contra el racismo, la discriminación racial y formas conexas de intolerancia. Organización de los Estados Americanos, La Antigua, Guatemala, 5 de junio de 2013. Recuperado de https://bit.ly/3wPlcx7 
Convención Interamericana para prevenir, sancionar y erradicar la violencia contra la mujer. Organización de los Estados Americanos, Belém do Pará, Brasil, 6 de septiembre de 1994. Recuperado de https://bit.ly/3d90d0r

Convención Internacional sobre la Eliminación de todas las Formas de Discriminación Racial. Adoptada y abierta a la firma y ratificación por la Asamblea General en su resolución 2106 A (XX), de 21 de diciembre de 1965. Organización de las Naciones Unidas, 4 de enero de 1969. Recuperado de https://bit.ly/3hmZIYq

Convención sobre la eliminación de todas las formas de discriminación contra la mujer. Adoptada y abierta a la firma y ratificación, o adhesión, por la Asamblea General en su resolución 34/180, de 18 de diciembre de 1979. Organización de las Naciones Unidas, 3 de septiembre de 1981. Recuperado de https://bit.ly/3jWVVNH

Convención sobre los Derechos del Niño. Adoptada y abierta a la firma y ratificación por la Asamblea General en su resolución 44/25, de 20 de noviembre de 1989. Organización de las Naciones Unidas, 2 de septiembre de 1990. Recuperado de https://bit.ly/34jrSrm

Convenio $\mathrm{N}^{\circ} 169$. Sobre pueblos indígenas y tribales. Organización Internacional del Trabajo, 5 de septiembre de 1991. Recuperado de https://bit.ly/2ITIdut

Couso Salas, J.(2013). Mapuches y derecho penal. En H. Olea Rodríguez (Ed.), Derecho y pueblo mapuche: aportes para la discusión (pp. 155-214), Santiago: Centro de Derechos Humanos Universidad Diego Portales. Recuperado de https://bit.ly/2TXpOIZ

Declaración Americana sobre los Derechos de los Pueblos Indígenas. Organización de los Estados Americanos, 14 de junio de 2016. Recuperado de https://bit.ly/3jimylY

Declaración de Naciones Unidas sobre los Derechos de los Pueblos Indígenas. Organización de la Naciones Unidas, 13 de septiembre de 2007. Recuperada de https://bit.ly/3jmbLh2

Defensoría del Pueblo. Unidad de Atención Integral a Víctimas de la Violencia. (2011). Protocolo de orientación y asesoría para las víctimas de violaciones de los derechos humanos y del derecho internacional humanitario pertenecientes a pueblos indígenas. Recuperado de https://bit.ly/3 kfISIH

Declaración Universal de Derechos Humanos, Resolución 217 A (III), (Asamblea General de las Naciones Unidas 10 de diciembre de 1948). Recuperado https://bit.ly/3k1LAz

Decreto con Fuerza de Ley $\mathrm{N}^{\circ} 1$. Fija el texto refundido, coordinado y sistematizado de la Ley No 18.695, Orgánica Constitucional de Municipalidades. Diario Oficial de la República de Chile, Santiago, Chile, 26 de julio de 2006. Recuperado de http://bcn.cl/2f796 
Bases normativas para un protocolo de atención a usuarios indígenas...

Decreto Legislativo N 635. Código Penal. El Peruano, Diario Oficial, Lima, Perú, 8 de abril de 1991. Recuperado de https://bit.ly/36p4Saq

Decreto Legislativo N 957. Código Procesal Penal. El Peruano, Diario Oficial, Lima, Perú, 1 de julio de 2006. Recuperado de https://bit.ly/3wxom7z

Decreto Ley N ${ }^{\circ} 107$. Código Procesal Civil y Mercantil. Diario de Centro América, Ciudad de Guatemala, Guatemala, 19 de diciembre de 1963. Recuperado de https://bit.ly/3yFyA7h

Decreto $N^{\circ} 19$. Ley de Idiomas Nacionales. Diario de Centro América, Ciudad de Guatemala, Guatemala, 26 de mayo de 2003. Recuperado de https://bit.ly/3hR6krv

Decreto $N^{\circ} 51$. Código Procesal Penal. Diario de Centro América, Ciudad de Guatemala, Guatemala, 14 de diciembre de 1992. Recuperado de https://bit.ly/3qXchY0

Decreto $N^{\circ}$ 52. Ley Marco de los Acuerdos de Paz. Diario de Centro América, Ciudad de Guatemala, Guatemala, 7 de septiembre de 2005. Recuperado de https://bit.ly/2VsnZOQ

Decreto $\mathrm{N}^{\circ} 66$. Aprueba reglamento que regula el procedimiento de consulta indígena en virtud del artículo 6 № 1 letra a) y nº 2 del Convenio № 169 de la Organización Internacional Del Trabajo y deroga normativa que indica. Diario Oficial de la República de Chile, Santiago, Chile, 4 de marzo de 2014. Recuperado de http://bcn.cl/2lp47

Decreto $\mathrm{N}^{\circ}$ 307. Fija el texto refundido, coordinado y sistematizado de la Ley 15.231, sobre organización y atribuciones de los Juzgados de Policia Local. Diario Oficial de la República de Chile, Santiago, Chile, 23 de mayo de 1978. Recuperado de http://bcn.cl/2hgzf

Decreto Supremo № 017. Texto Único y ordenado de la Ley Orgánica del Poder Judicial. El Peruano, Diario Oficial, Lima, Perú, 2 de junio de 1993. Recuperado de https://bit.ly/2TKRHhD

Decreto Supremo № 025. Aprueban reglamento de la Ley de Rondas Campesinas. El Peruano, Diario Oficial, Lima, Perú, 30 de diciembre de 2003. Recuperado de https://bit.ly/3hUenDT

Decretos N 1.400 y 2.019. Código de Procedimiento Civil. Diario Oficial, Bogotá, 26 de octubre de 1970. Recuperado de https://bit.ly/3hOeHUO

Defensoría de la Mujer Indígena. (s.f.). Manual de atención jurídica: área de atención integral de casos. Recuperado de https://bit.ly/2UyAkjQ

Defesoría Penal Pública. (2008). La defensa de imputados indígenas en la Defensoría Penal Pública. Recuperado de https://bit.ly/2SVvmNJ 
Defesoría Penal Pública. (2010). Modelo de defensa penal para Imputados indigenas. Recuperado de https://bit.ly/3Abomx8

Emmerson, B. (2014, Abril 14). Misión a Chile. Informe del Relator Especial sobre la promoción y protección de los derechos humanos y las libertades fundamentales en la lucha contra el terrorismo (Informe N A/HRC/25/59/Add.2). Consejo de Derechos Humanos - Asamblea General - Naciones Unidas [Archivo PDF]. Recuperado de https://bit.ly/3jX28cl

Equipo FONDEF ID 16I10424. (s.f.). Pau-Mapu: Presentación del protocolo de atención a usuarios y usuarias mapuche de los Juzgados y Tribunales de la Macrorregión Sur. Recuperado de https://bit.ly/2SGOEYW

Espinel Gaona, M. A. (2016). Guía para la transversalización del principio de interculturalidad en la justicia ordinaria. Quito: Consejo de la Judicatura. Recuperado de https://bit.ly/3xuEFDz

Faundes Peñafiel, J. J., y Le Bonniec, F. (2020). Comparando la cultura jurídica desde el derecho a la identidad cultural en Brasil y Chile. Revista de Direito Internacional (Online), 17(1), 144-179. doi: 10.5102/rdi.v17i1.6555

Gauché Marchetti, X. A. (2014). Análisis crítico de la Ley № 20.609, que establece medidas contra la discriminación, a la luz del derecho internacional de los derechos humanos y las convenciones de la OEA sobre discriminación de 2013. Revista chilena de derecho y ciencia política (En línea), 5(1), 11-58. Recuperado de https://bit.ly/3xu4oeZ

Harris-Short, S. (2012). Aboriginal child welfare, self-government and the rights of indigenous children: protecting the vulnerable under international Law. London: Routledge. doi: $10.4324 / 9781315565408$

Hoja de Ruta de la Justicia Intercultural. Resolución Administrativa N 499-2012-P-PJ (Corte Suprema de Justicia de la República del Perú 17 de diciembre de 2012). Recuperado de https://bit.ly/3AOc12g

Instituto Interamericano de Derechos Humanos. (2015). Protocolo de acceso a la justicia penal intercultural y coordinación interinstitucional, Guatemala. Recuperado de https://bit.ly/3hMG8OQ

Instituto Interamericano de Derechos Humanos. (2014a). Protocolo de actuación de justicia intercultural: Chiapas, México. Recuperado de https://bit.ly/3hvl7Jw

Instituto Interamericano de Derechos Humanos. (2014b). Protocolo de actuación de justicia intercultural: Oaxaca, México. Recuperado de https://bit.ly/3wvDlyE

Juez policía local ausencias descuentos, Dictamen № 6962 (Contraloría General de la República 29 de febrero de 2000). Recuperado de https://bit.ly/2TFbzlT 
Lagarde y de los Ríos, M. M. (1988). La triple opresión de las mujeres indias. México indígena, 4(21), 11-15.

Lagarde y de los Ríos, M. M. (1993). Los cautiverios de las mujeres: madresposas, monjas, putas y locas. México D.F.: UNAM.

Lara Escalona, M. D., y Hernández Badilla, P. A. (2015). Protocolo de atención a mujeres indígenas extranjeras privadas de libertad. Madrid: EUROsociAL. Recuperado de https://bit.ly/3vtxZnl

Le Bonniec, F., Millaman Reinao, R., Villegas Díaz, M., Payàs Puigarnau, G., Berho CastiIlo, M., Nahuelcheo Queupucura, P., Martínez Cañoles, W., y Huenchucoy Millao, L. M. (2019). Protocolo de atención a usuarios y usuarias mapuche en tribunales y juzgados de la Macrorregión Sur. Temuco: Universidad Católica del Temuco. Recuperado de https://bit.ly/3k1 KPHd

Ley Agraria. Diario Oficial de la Federación, México, 26 de febrero de 1992. Recuperado de https://bit.ly/3wuHWBn

Ley Federal para Prevenir y Eliminar la Discriminación. Diario Oficial de la Federación, México, 11 de junio de 2003. Recuperado de https://bit.ly/3AFdvf4

Ley General de Derechos Lingüísticos de los Pueblos Indígenas. Diario Oficial de la Federación, México, 13 de marzo de 2003. Recuperado de https://bit.ly/3hsDNto

Ley para el Tratamiento de Menores Infractores, para el Distrito Federal en Materia Común y para toda la República en Materia Federal. Diario Oficial de la Federación, México, 24 de diciembre de 1991. Recuperado de https://bit.ly/3AJipHT

Ley $N^{\circ}$ 025. Ley del Órgano Judicial. Gaceta Oficial del Estado Plurinacional de Bolivia, La Paz, Bolivia, 24 de junio de 2010. Recuperado de https://bit.ly/3qWsLzA

Ley $N^{\circ}$ 027. Ley del Tribunal Constitucional Plurinacional. Gaceta Oficial del Estado Plurinacional de Bolivia, La Paz, Bolivia, 6 de julio de 2010. Recuperado de https://bit.ly/3hOUqyp

Ley $N^{\circ}$ 045. Contra el racismo y toda forma de discriminación. Gaceta Oficial del Estado Plurinacional de Bolivia, La Paz, Bolivia, 8 de octubre de 2010. Recuperado de https://bit.ly/3hMF5OZ

Ley $N^{\circ}$ 073. Ley de Deslinde Jurisdiccional. Gaceta Oficial del Estado Plurinacional de Bolivia, La Paz, Bolivia, 29 de diciembre de 2010. Recuperado de https://bit.ly/3xnnkfD

Ley $\mathrm{N}^{\circ}$ 757. Ley de trato digno y equitativo a Pueblos Indígenas y AfroDescendientes. La Gaceta, Diario Oficial, Managua, Nicaragua, 26 de mayo de 2011. Recuperado de https://bit.ly/3qXbRAU 
Ley N ${ }^{\circ}$ 904. Estatuto de las Comunidades Indígenas. Gaceta Oficial de la República del Paraguay, Asunción, Paraguay, 10 de diciembre de 1981. Recuperado de https://bit.ly/3xwvkLw

Ley N ${ }^{\circ}$ 906. Código de Procedimiento Penal. Diario Oficial, Bogotá, 31 de agosto de 2004. Recuperado de https://bit.ly/3xvC2kO

Ley No 1.286. Código Procesal Penal. Gaceta Oficial de la República del Paraguay, Asunción, Paraguay, 14 de julio de 1998. Recuperado de https://bit.ly/3jYM2iE

Ley № 1.337. Código Procesal Civil. Gaceta Oficial de la República del Paraguay, Asunción, Paraguay, 29 de octubre de 1988. Recuperado de https://bit.ly/3xzbBuv

Ley $N^{\circ}$ 1.381. Ley de Lenguas Nativas. Diario Oficial, Bogotá, Colombia, 25 de enero de 2010. Recuperado de https://bit.ly/3kfysHV

Ley N ${ }^{\circ}$ 1.552. Código de Procedimiento Civil. Diario Oficial de la República de Chile, Santiago, Chile, 30 de agosto de 1902. Recuperado de http://bcn.cl/2f6oc

Ley N 7.421. Código Orgánico de Tribunales. Diario Oficial de la República de Chile, Santiago, Chile, 9 de julio de 1943. Recuperado de http://bcn.cl/2fa3i

Ley $\mathrm{N}^{\circ}$ 18.883. Aprueba estatuto administrativo para funcionarios municipales. Diario Oficial de la República de Chile, Santiago, Chile, 29 de diciembre de 1989. Recuperado de http://bcn.cl/2f6zg

Ley $\mathrm{N}^{\circ}$ 19.253. Establece normas sobre protección, fomento y desarrollo de los indígenas, y crea la Corporacion Nacional de Desarrollo Indígena. Diario Oficial de la República de Chile, Santiago, Chile, 5 de octubre de 1993. Recuperado de http://bcn.cl/2f7n5

Ley N 19.696. Establece Código Procesal Penal. Diario Oficial de la República de Chile, Santiago, Chile, 12 de octubre de 2000. Recuperado de http://bcn.cl/2f7dm

Ley $N^{\circ}$ 20.609. Establece medidas contra la discriminación. Diario Oficial de la República de Chile, Santiago, Chile, 24 de julio de 2012. Recuperado de http://bcn.cl/2g7mr

Ley No 27.908. Ley de Rondas Campesinas. El Peruano, Diario Oficial, Lima, Perú, 8 de enero 2003. Recuperado de https://bit.ly/3r3wyv9

Ley $N^{\circ} 29.735$. Ley que regula el uso, preservación, desarrollo, recuperación, fomento y difusión de las lenguas originarias del Perú. El Peruano, Diario Oficial, Lima, Perú, 5 de julio de 2011. Recuperado de https://bit.ly/3hRUa1C

Ley N² 29.824. Ley de Justicia de Paz. El Peruano, Diario Oficial, Lima, Perú, 3 de enero de 2012. Recuperado de https://bit.ly/36rgs57 
Martínez Cañoles, W. (2019). La producción de la diferencia en los espacios de justicia: una aproximación etnográfica al proceso de atención de usuarios mapuche en tribunales de justicia de La Araucanía (Actividad Formativa Equivalente para optar al grado de Magíster en Antropología). Universidad Católica de Temuco.

Mecanismo de expertos sobre los derechos de los pueblos indígenas (2012, Abril 30). Informe de seguimiento sobre los pueblos indígenas y el derecho a participar en la adopción de decisiones, con especial atención a las industrias extractivas (Informe no. A/HRC/EMRIP/2012/2). Consejo de Derechos Humanos - Asamblea General - Naciones Unidas [Archivo PDF]. Recuperado de https://bit.ly/3ww8imu

Melin Pehuen, M., Coliqueo Collipal, P., Curihuinca Neira, E., y Royo Letelier, M. (2016) Az mapu: una aproximación al Sistema Normativo Mapuche desde el Rakizuam y el Derecho Propio. Santiago: INDH. Recuperado de https://bit.ly/3vo0h2s

Ministerio de Justicia y Transparencia Institucional. (2017). Protocolo de prevención, atención y sanción a toda forma de vulneración a la integridad sexual de niñas, niños y adolescentes. Recuperado de https://bit.ly/2UylLvF

Ministerio de Obras Públicas. (s.f.). Asuntos Indígenas. Recuperada de https://bit.ly/2UFCILu

Molina Rivero, R. (2008). La justicia comunitaria en Bolivia: cambios y continuidades. En Derechos, costumbres y jurisdicciones indígenas en la América Latina contemporánea (pp. 95-126). Madrid: Centro de Estudios Políticos y Constitucionales.

Mosquitia Asla Takanka. (2012). Protocolo Bio-cultural del Pueblo Indígena Miskitu: el derecho al consentimiento libre, previo e informado en nuestro territorio de La Muskitia Hondureña. Recuperado de https://bit.ly/2SZXO0Z

Nash Rojas, C., Núñez Donald, C., y Bustamante Soldevilla, M. (2014). Derechos Humanos y pueblos indígenas en Chile: análisis jurisprudencial para procesos de consulta en el marco del Convenio 169 de la OIT. Santiago: Centro de Derechos Humanos, Universidad de Chile. Recuperado de https://bit.ly/3iMkvA9

Norín Catrimán y otros (dirigentes, miembros y activista del pueblo indígena mapuche) Vs. Chile, Sentencia Serie C No 279 (Corte Interamericana de Derechos Humanos 29 de mayo de 2014). Recuperado de https://bit.ly/3cNjlAV

Observaciones finales sobre el sexto informe periódico de Chile. Naciones Unidas, Comité de Derechos Humanos, 13 de agosto de 2014, CCPR/C/CHL/CO/6. Recuperado de https://bit.ly/2TTaebn

Observación General N 9. Los derechos de los niños con discapacidad. Convención, Naciones Unidas, Comité de los Derechos del Niño, 27 de febrero 2007, CRC/C/GC/9. Recuperado de https://bit.ly/3hp6wze 
Observación General N¹1. Los niños indígenas y sus derechos en virtud de la Convención. Naciones Unidas, Comité de los Derechos del Niño, 12 de febrero de 2009, CRC/C/GC/11. Recuperado de https://bit.ly/3xmQMSv

Oficina Nacional de Justicia de Paz y Justicia Indígena del Poder Judicial. (2015). Protocolos de coordinación para una justicia intercultural. Protocolo de coordinación entre sistemas de justicia. Protocolo de actuación en procesos judiciales que involucren a comuneros y ronderos. Recuperado de https://bit.ly/3yHPJ04

Oficina Nacional de Justicia de Paz y Justicia Indígena del Poder Judicial. (2014). Protocolo de atención y orientación legal con enfoque intercultural: dirigido a funcionarios de Ucayali y Loreto. Recuperado de https://bit.ly/3ww98zN

Pacto Internacional de Derechos Civiles y Políticos. Adoptado y abierto a la firma, ratificación y adhesión por la Asamblea General en su resolución 2200 A (XXI), de 16 de diciembre de 1966. Organización de las Naciones Unidas, 23 de marzo de 1976. Recuperado de https://bit.ly/3ks7YjE

Plan regulador comunal de Chile Chico, Dictamen N 44051 (Contraloría General de la República 19 de diciembre de 2017). Recuperado de https://bit.ly/3iOaa6L

Planes reguladores, Dictamen №31587 (Contraloría General de la República 22 de abril de 2015). Recuperado de https://bit.ly/3q0yx2R

Poder Judicial de la República de Chile (2010). Protocolos de atención: modelo de atención de usuarios del Poder Judicial.

Poder Judicial del Estado de Tabasco. (2014). Protocolo del Poder Judicial del Estado de Tabasco: para quienes imparten justicia en casos de personas, comunidades y pueblos indígenas. Recuperado de https://bit.ly/3wt5iHx

Prieto Giménez, E. (2017). Protocolo de actuación para una Justicia Intercultural: los pueblos indígenas. Asunción: Corte Suprema de Justicia. Recuperado de https://bit.ly/3qX5A8q

Procuraduría para la Defensa de los Derechos Humanos. (2012). Protocolo de atencion: Afrodescendientes. Recuperado de https://bit.ly/3wuu8a3

Propuesta de modificación a la Constitución Política de Costa Rica relacionada con la naturalización, Opinión Consultiva OC-4/84 (Corte Interamericana de Derechos Humanos 19 de enero de 1984). Recuperado de https://bit.ly/3iLv3j0

Pueblo Indígena Kichwa de Sarayaku Vs. Ecuador, Sentencia Serie C No 245 (Corte Interamericana de Derechos Humanos 27 de junio de 2012). Recuperado de https://bit.ly/2U3DIIM 
Pueblo Saramaka vs. Surinam, Sentencia Serie C No 172 (Corte Interamericana de Derechos Humanos 28 de noviembre de 2007). Recuperado de https://bit.ly/2SyZsqm

Requerimiento presentado por un grupo de Diputados respecto de la inconstitucionalidad del Convenio № 169, sobre Pueblos Indígenas y Tribales en Países Independientes, adoptado por la Organización Internacional del Trabajo, el 27 de junio de 1989, Rol N 309-00 (Tribunal Constitucional 4 de agosto de 2000) Recuperado de https://bit.ly/3wCryjg

Roht-Arriaza, N. (2017). Guatemala: lessons for transitional justice. En C. Lawther, L. Moffett, y D. Jacobs (Eds.). Research handbook on transitional justice (pp. 445-465). Cheltenham: Edward Elgar. doi: 10.4337/9781781955314.00032

Secretaría Permanente de Cumbre Judicial Iberoamericana. (2008). Reglas de Brasilia sobre acceso a la Justicia en condición de vulnerabilidad. En XIV Cumbre Judicial Iberoamericana. Declaración de Brasilia: Más iguales, más justos, más solidarios. 4, 5 y 6 de marzo de 2008 Brasilia - Brasil (pp. 31-44). Madrid: Consejo General del Poder Judicial. Recuperado de https://bit.ly/2VrXBEP

Shelton, D. (2008). Prohibición de discriminación en el Derecho Internacional de los Derechos Humanos. Anuario de derechos humanos (Santiago. En línea), (4), 15-39. Recuperado de https://bit.ly/3zxDrlX

Stavenhagen, R. (2004, Enero 26). Los derechos humanos y las cuestiones indígenas. Informe del Relator Especial sobre la situación de los derechos humanos y las libertades fundamentales de los indígenas (Informe NE/CN.4/2004/80). Comisión de Derechos Humanos - Consejo Económico y Social - Naciones Unidas. [Archivo PDF]. Recuperado de https://bit.ly/2UwLwxJ

Stavenhagen, R. (2007, Febrero 27). Aplicación de la Resolución 60/251 de la Asamblea General, de 15 de Marzo de 2006, Titulada "Consejo de Derechos Humanos". Informe del Relator Especial sobre la situación de los derechos humanos y las libertades fundamentales de los indígenas (Informe $\mathrm{N}^{\circ} \mathrm{A} / \mathrm{HRC} / 4 / 32$ ). Consejo de Derechos Humanos - Asamblea General - Naciones Unidas [Archivo PDF]. Recuperado de https://bit.ly/3wtEQNQ

Suprema Corte de Justicia de la Nación. (2014). Protocolo Iberoamericano de actuación judicial: para mejorar el acceso a la justicia de personas con discapacidad, migrantes, niñas, niños, adolescentes, comunidades y pueblos indígenas. Recuperado de https://bit.ly/3yGp43L

Suprema Corte de Justicia de la Nación. (2013). Protocolo de actuación: para quienes imparten justicia en casos que involucren derechos de personas, comunidades y pueblos indígenas. Recuperado de https://bit.ly/3ylcKzY 
Trujillo Vásquez, J. C. (2012). Plurinacionalidad y Constitución. En B. de Sousa Santos y A. Grijalva Jiménez (Eds.), Justicia indígena, plurinacionalidad e interculturalidad en Ecuador (pp. 305-316). Quito: Abya Yala. Recuperado de https://bit.ly/3cPeA9X

Véliz Fanco y otros Vs. Guatemala, Sentencia Serie C No 277 (Corte Interamericana de Derechos Humanos 19 de mayo de 2014). Recuperado de https://bit.ly/3xtDjZ4

Villegas Díaz, M. y Mella-Seguel, E. (2017) Cuando la costumbre se vuelve ley: la cuestión penal y la pervivencia de los sistemas sancionatorios indígenas en Chile. Santiago: LOM.

Villegas Díaz, M. (2012). Entre la exculpación y la justificación: Apuntes de legislación comparada latinoamericana sobre pluralismo jurídico y derecho penal. Revista de derecho (Valdivia), 25(2), 177-205. doi: 10.4067/S0718-09502012000200008

Vivienda y urbanismo, planes reguladores o planos reguladores, Dictamen № 597 (Contraloría General de la República 8 de enero de 2018). Recuperado de https://bit.ly/3wysXY1

Vivienda y urbanismo, planes reguladores, Dictamen N ${ }^{\circ} 40374$ (Contraloría General de la República 20 de mayo de 2015). Recuperado de https://bit.ly/3gwq6sX

Vivienda y urbanismo, planes reguladores o planos reguladores, consulta indígena, Dictamen N³0349 (Contraloría General de la República 22 de abril de 2016). Recuperado de https://bit.ly/3iMJ5RJ

\section{Para citar este artículo bajo Norma APA 6a ed.}

Francesconi, L. y Villegas Díaz, M. (2021). Bases normativas para un protocolo de atención a usuarios indígenas en los tribunales chilenos: especial referencia a los Juzgados de Policía Local. Revista de Derecho (Coquimbo. En línea), 28, e3146. https://doi.org/10.22199/issn.0718-9753-2021-0016

Copyright del articulo: ()2021 Lavinia Francesconi y Myrna Villegas

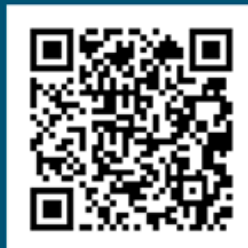

DOI

(cc) BY Este es un artículo de acceso abierto, bajo licencia Creative Commons BY 4.0. 